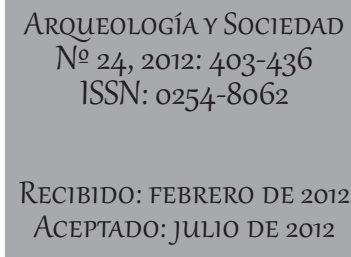

\title{
EL CENTRO ADMINISTRATIVO INCA DE TAMBO VIEJO
}

\author{
DOROTHY MENZEL \\ INSTITUTE OF ANDEAN STUDIES \\ FRANCIS A. RIDDELL ${ }^{\dagger}$ \\ LIDIO M. VALDEZ* \\ MACEWAN UNIVERSITY, CANADA \\ valdezcardenasl@macewan.ca
}

\section{RESUMEN}

En este artículo presentamos los resultados de los trabajos de investigación efectuados en el centro administrativo Inca de Tambo Viejo, el único de su carácter establecido en el valle de Acarí, en la costa sur del Perú. Este estudio revela, entre otros, la complejidad arquitectónica del sitio, así como su inmensa dimensión. A su vez, el presente estudio enseña que el sitio presenta una larga secuencia de ocupación humana iniciada a comienzos del periodo Intermedio Temprano y que continuó hasta el periodo colonial. Este estudio tiene como foco de análisis la ocupación Inca, la misma que es evaluada teniendo en consideración la arquitectura de Tambo Viejo. Dicho análisis revela que Tambo Viejo fue construido siguiendo un diseño Inca; sin embargo, la arquitectura es local y sugiere que éste fue edificado por constructores locales. Esta observación permite sostener que la administración Inca se adaptó a los patrones constructivos locales.

Palabras Clave: Estado Inca, Costa Sur del Perú, Acarí, Tambo Viejo, Arquitectura.

\begin{abstract}
In this article we present the results of the archaeological studies carried out at the Inca administrative center of Tambo Viejo, the only facility of its character built by the Inca in the Acari Valley of the Peruvian south coast region. This study reveals, among others, the architectural complexity of the site and its enormous size. Likewise, this study demonstrates that Tambo Viejo has a long sequence of human occupation that began early in the Early Intermediate period and continued to colonial times. In this paper we evaluate the Inca ocupation of the site, taking into consideration the architecture. This analysis demonstrates that Tambo Viejo was established following an Inca plan; however, the architecture is local, suggesting that the builders of the site were from Acari. This observation allows us to argue that the Inca administration adapted to local construction patterns.
\end{abstract}

KeYwords: Inca State, South Coast of Peru, Acari, Tambo Viejo, Architecture.

* Correspondencias dirigir a esta dirección: valdezcardenasl@macewan.ca. 


\section{INTRODUCCIÓN}

Al inspeccionar el camino Inca de la costa sur del Perú, en 1953 Víctor von Hagen (1955) seleccionó al sitio de Tambo Viejo del valle de Acarí para los propósitos de llevar adelante un estudio arqueológico y evaluar la función de este centro administrativo que efectivamente está articulado al camino real Inca que atraviesa la costa peruana (Cieza de León 1973: 185; Hyslop 1984). El camino Inca llega desde el valle de Nasca y es visible en la pampa ubicada al oeste de Tambo Viejo e ingresa hacia una amplia plaza del sitio. Luego cruza por completo la referida plaza y se dirige hacia el río Acarí, para continuar en la margen opuesta y dirigirse hacia el siguiente valle de Yauca. Un puente colgante debió existir al lado Este de Tambo Viejo, pero que ha desaparecido en el transcurso de los años. Además del camino Inca, el plano de un sector importante del sitio arqueológico es de origen Inca, y es el único sitio de su carácter para todo el valle de Acarí. Estas fueron algunas de las razones que motivaron llevar adelante los trabajos de investigación arqueológica en Tambo Viejo.

Poco tiempo después de la selección hecha por von Hagen, y en coordinación con él y John H. Rowe, en marzo de 1954 se efectuaron los primeros trabajos de investigación arqueológica en Tambo Viejo (Valdez 2009a: 256). El objetivo central de dicha investigación fue, primero, trazar la antigua historia de ocupación del sitio y, segundo, situar Tambo Viejo en el contexto Inca. Para su efecto, el procedimiento a seguir fue diverso, la misma que incluyó la preparación del indispensable plano del sitio arqueológico, hacer una descripción lo más detallado posible de la arquitectura del sitio, efectuar algunas excavaciones de prueba y analizar la cerámica. Al mismo tiempo, y con la finalidad de situar Tambo Viejo en el contexto local, durante el curso de los trabajos en el sitio, se hizo el esfuerzo de recorrer una sección del valle de Acarí para registrar otros sitios arqueológicos. Este procedimiento permitió registrar varios sitios vecinos a Tambo Viejo y recuperar de cada sitio registrado muestras diagnosticas de cerámica, útiles para establecer la secuencia de ocupación humana del valle de Acarí (Menzel y Riddell 1986). Desde entonces, varios trabajos han sido efectuados en Tambo Viejo (Kent y Kowta 1994; Valdez 1996) y el valle de Acarí en general, y es el conjunto de toda esta información que ayuda a explicar mejor la situación del sitio y por extensión del valle de Acarí al tiempo de la ocupación Inca.

Durante el curso de los trabajos se hizo evidente que el sitio fue objeto de una sistemática destrucción. Primero, en 1954 a diario entraron al complejo arqueológico de Tambo Viejo camiones para transportar las piedras que fueron sistemáticamente removidos de las antiguas estructuras. Con esto, no sólo estructuras completas desaparecieron, sino también los camiones abrieron brechas en todas las direcciones, obscureciendo en el proceso el plano original de las estructuras. Segundo, desde mediados de 1980 Tambo Viejo es objeto de una planeada destrucción, esta vez como resultado del establecimiento de nuevas construcciones especialmente en su sector norte. Este último es consecuencia de la rápida y descontrolada expansión del poblado de Acarí (Valdez 1996). De este modo, una gran extensión del sitio arqueológico ha sido totalmente destruida. Por ejemplo, dos de los tres muros observadas en 1954 al lado oeste del sitio han sido del todo destruidos, mientras que sólo quedan pequeñas secciones del tercero. Del mismo modo, varias estructuras del lado norte del sitio han sido del todo borradas como resultado de las nuevas construcciones. Así queda claro que si las autoridades responsables de la protección de los monumentos arqueológicos no toman las necesarias medidas que garanticen la integridad del sitio, existe la alarmante posibilidad que Tambo Viejo desaparezca por completo entre una o dos décadas. De ocurrir esto, sería una pérdida irreparable, especialmente si se tiene en consideración que se conoce muy poco del sitio.

En este trabajo, primero discutimos la ubicación de Tambo Viejo en el valle de Acarí y luego exponemos los trabajos efectuados en el sitio. En la tercera sección presentamos la descripción de los varios sectores de Tambo Viejo. En la cuarta sección se describen las dos excavaciones de prueba. En la quinta sección se discute la situación del valle de Acarí al momento de la llegada Inca y durante el tiempo de existencia de Tambo Viejo. En seguida se evalúa la relación de Tambo Viejo con otros sitios Inca, especialmente con aquellos establecidos en la costa sur. Se debe anotar que esta comparación 
es a nivel arquitectónico. Finalmente, se incluye una breve discusión de los hallazgos más sobresalientes. Esta sección es breve, pero será eventualmente complementada y ampliada al discutirse la cerámica de Tambo Viejo, que por razones de extensión no es incluido en este trabajo. Anticipamos que el tratado detallado de la cerámica aparecerá en un número próximo de esta revista.

\section{La ubicación del Centro Inca de TAmbo Viejo}

El siguiente valle al sur de Nasca es Acarí, formado por el río del mismo nombre (Fig. 1). Estos dos valles están separados por una pampa desértica que cubre aproximadamente $100 \mathrm{~km}$. El Río Acarí nace en las cercanías de Lucanas y Puquio, desde donde recorre en una dirección norte - sur. En gran parte de su tramo, el río recorre entre montañas de formación rocosa, hecho que hace que el valle sea angosto. Sólo en sus últimos $25 \mathrm{~km}$ de recorrido, éste cruza la pampa desértica, pero incluso ahí en lugar de irrigar un área más extensa hace un corte profundo y desemboca en el océano (Valdez 2009b: 408). Como resultado, el valle no sólo es angosto, sino también con limitadas áreas irrigables y de importancia agrícola. Además, una mayor extensión de los suelos agrícolamente importantes se encuentra a lo largo de los últimos $25 \mathrm{~km}$ de recorrido del río; y no sorprende que ésta sea la sección de mayor importancia agrícola de todo el valle. Como se discute más adelante, Tambo Viejo fue edificado en la parte intermedia de la sección agrícolamente más fértil del valle.

No obstante las limitaciones agrícolas arriba anotadas, el valle de Acarí está repleto de sitios arqueológicos, muchos de los cuales muy accesibles (Rowe 1956: 137), y que en general representan una ocupación continua que abarca desde el Periodo Inicial (circa 800 a. C.) hasta el presente (Valdez 2000a). La evidencia más temprana está representada por el sitio de Hacha (Rowe 1963; Riddell y Valdez 1987; Robinson 1994). A su vez, es de mucho interés observar que el material cultural recuperado de la superficie de los varios sitios arqueológicos del valle indica que por aproximadamente 2000 años, los residentes del valle de Acarí mantuvieron una continua conexión con sus vecinos de los valles de Nasca e Ica. Por lo tanto, existen evidencias concretas que señalan que Acarí constituyó el valle más sureño que participó activamente en la antigua historia de la costa sur. En contraste, el valle de Yauca, ubicado inmediatamente al sur de Acarí, es periférico y la evidencia material es distinta al encontrado en Acarí.

Tambo Viejo se encuentra aproximadamente a $20 \mathrm{~km}$ del mar e inmediatamente al sur del actual poblado de Acarí. El lugar donde el sitio fue establecido ofrece características únicas como, por ejemplo, éste se encuentra adyacente a la sección más amplia y fértil del valle. Este también es el punto donde las pendientes occidentales de los cerros llegan a su fin al lado oeste del sitio y abren paso a la formación de la pampa desértica. Al lado opuesto, los cerros continúan por algunos kilómetros más, pero que también desaparecen a una distancia intermedia entre Tambo Viejo y el mar. De este modo, Tambo Viejo no está en una sección cerrada y angosta del valle. Por último, el sitio fue construido sobre una amplia terraza de formación aluvial que tiene una elevación promedio de $25 \mathrm{~m}$ aproximadamente, elevación ésta que permite mantener una visibilidad sobre una buena extensión del valle. Así, Tambo Viejo estaba próximo a los campos de cultivo, pero sin ocupar terrenos que podrían ser utilizados para fines agrícolas.

Dada estas características, no parece ser una simple coincidencia que el Estado Inca optara por seleccionar este lugar para edificar su único establecimiento en este valle. La baja altura de los cerros precisamente al oeste de Tambo Viejo hizo de este lugar un punto conveniente para el camino Inca que cruza desde Nasca, donde se encuentra el sitio Inca de Paredones (Cieza de León 1973: 185; Morris y Von Hagen 2011:148-149), hacia el valle de Acarí. De esta manera, el camino no está del todo alejado de los cerros, como tampoco se pierde en medio del desierto. Es preciso anotar que a lo largo de la costa sur se ha notado que el lugar preferido para la construcción de los caminos por el Estado Inca fue precisamente el punto de fusión entre los cerros y la pampa del desierto. 


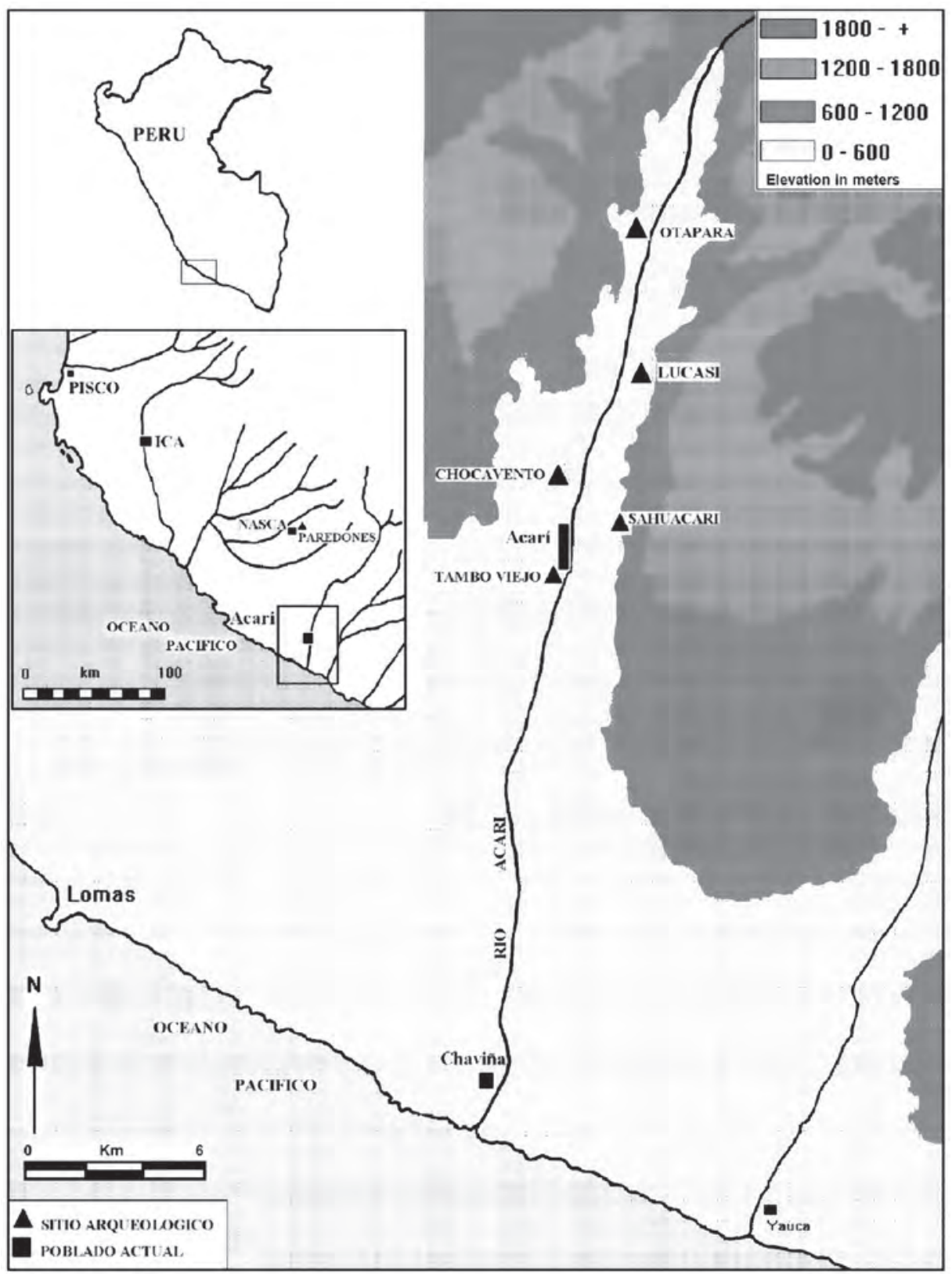

Figura 1. Mapa de ubicación del valle de Acarí y Tambo Viejo.

Importante es anotar que la costa sur del Perú entró en contacto con el naciente estado Inca en tiempos de Pachakuti, quien siguiendo la victoria cusqueña sobre los Chankas (Sarmiento de Gamboa 1999: 115-119) envió como emisario a su hermano Kapaq Yupanki a visitar a los valles costeños. Algunos detalles de este primer contacto quedaron preservados en Chincha (Cieza de León 1973: 183; Rowe 1945: 270), la misma que probablemente tomó lugar alrededor del año 1440 (Menzel 1959: 126). Este contacto inicial no significó en la conquista Inca de la costa sur; más bien, la conquista propia- 
mente dicha, recién se dio en tiempos de Tupaq Yupanki, padre de Wayna Kapaq, quien logró convertir a las poblaciones de la costa sur en súbditos del estado Inca. No obstante algunas discrepancias (ver D’Altroy 2002: 69), varias fuentes señalan, que al igual que Chincha, los pobladores de los valles de Ica, Nasca y Acarí aceptaron una incorporación pacífica al Tawantinsuyo (Menzel 1959: 126). Esta incorporación final debió haber tomado lugar aproximadamente en 1476.

Considerando la incorporación pacífica de la región al control Inca, las poblaciones de la costa sur en general, incluido Acarí, no fueron satisfactoriamente asimilados al modelo Inca (Rowe 1956: 148). Por lo tanto, a lo largo de la costa sur, los sitios de habitación del periodo Inca poseen poca o ninguna evidencia de la influencia Inca (Menzel 1959: 128). Además, es importante recordar que la ocupación Inca tuvo una duración muy corta en la costa sur, en tanto que en 1534 Francisco Pizarro mandó a establecer un asentamiento español en Zangalla ubicado en el valle de Pisco. Con posterioridad este lugar fue conocido como Lima la Vieja (Menzel 1976; Hyslop 1984: 111; Morris y von Hagen 2011: 144). Con la presencia de los españoles, la población indígena de la región fue convertida parte de las encomiendas de los residentes europeos establecidos en Lima la Vieja. Esta fue otra razón por la cual la ocupación Inca no dejó tan marcada su presencia en esta región.

\section{InVESTIGACIONES ARQUeOLógicas EN TAMBo Viejo}

En 1954 Tambo Viejo se extendía 1,5 km de norte a sur y 0,5 km de este a oeste (Fig. 2). Dicha extensión hacia de Tambo Viejo en el sitio más extenso de todo el valle y en uno de los más grandes de toda la costa sur (Menzel y Riddell 1986). Tal como se anotó líneas adelante, la proximidad de Tambo Viejo al actual poblado de Acarí ha resultado en un problema bastante serio que pone en peligro la misma integridad física del sitio arqueológico. En particular, durante las últimas décadas el poblado ha crecido considerablemente, afectando directamente al monumento arqueológico. La destrucción ya observada en 1954 continuó en las siguientes décadas (Valdez 1996: 40) y resultó en la destrucción de una porción considerable del sitio, especialmente en sus lados norte, oeste, y sur-oeste. Muros antiguos son a menudo derrumbados para extraer tanto piedras como adobes que vuelven a ser reutilizadas en las nuevas construcciones que vienen siendo levantadas en el sitio. Las piedras son retiradas en camiones, las mismas que al ingresar al complejo abren trochas que eventualmente se convierten en caminos que cruzan el sitio en diferentes direcciones; sumado todo este deterioro, no sólo se hace difícil percibir el plano original de Tambo Viejo, sino también la extensión original del sitio ha sido reducida considerablemente.

Dada la extensión del sitio y el desorden creado por la destrucción, el primer paso necesario durante el proceso de las investigaciones arqueológicas en Tambo Viejo fue elaborar el plano general del sitio. Un plano tenía el potencial de ayudar a definir el ordenamiento de las estructuras. Al mismo tiempo, el plano y una descripción detallada de las estructuras presentes podía ayudar a percibir tanto las semejanzas, como las diferencias de las varias estructuras. Dicho sea de paso, este plano elaborado en 1954 constituye la única fuente que revela la complejidad del sitio arqueológico de Tambo Viejo, sobre todo su gran extensión. Desde entonces, el sitio ha sufrido una tremenda transformación, que desafortunadamente continúa.

El plano y la inspección detallada de las estructuras presentes en las varias secciones del sitio, permitieron determinar que el conjunto arqueológico de Tambo Viejo consiste de diferentes unidades arquitectónicas. Entre estas destaca un primer sector identificado como área A y que presenta las estructuras mejor preservadas de todo el sitio. El área A se encuentra al extremo sur-este del conjunto arqueológico; en su extremo norte, el área A dispone de un amplio espacio vacío identificado como plaza 1. Una segunda plaza, la plaza 2, aparece en la parte media de las estructuras del lado sur. Este fue el lugar donde el centro administrativo Inca había sido establecido y constituye el área de mayor importancia de la ocupación Inca. 


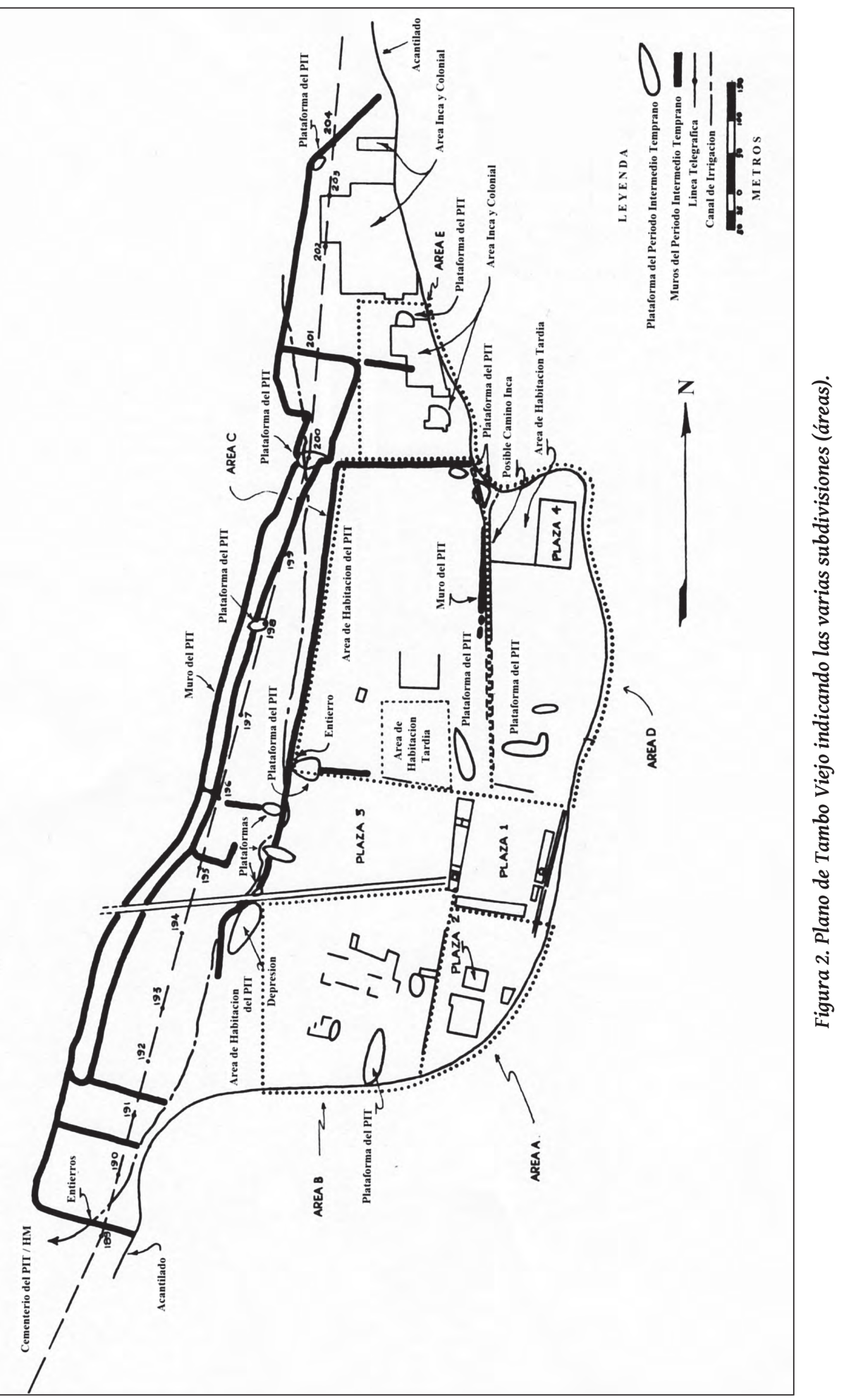


Un segundo sector identificado como área B se ubica inmediatamente al oeste de área A, pero separado del primero por un muro que se extiende de norte a sur. Las estructuras de esta área son menos elaboradas que las del anterior, aunque parecen estar relacionados al anterior. Al lado norte de área B aparece un amplio espacio vacío identificado como plaza 3 y que es cortado de este a oeste por el camino Inca que ingresa al sitio proveniente del valle de Nasca. Un tercer sector identificado como área $\mathrm{C}$ aparece inmediatamente al norte y oeste de la plaza 3. Esta nueva área está asociada a extensos muros perimétricos establecidos al lado oeste del sitio y, tal como se menciona en mayor detalle líneas más adelante, constituye la evidencia de ocupación más antigua del sitio (Valdez 2012). Inmediatamente al norte de área $\mathrm{A}$ y al este de área $\mathrm{C}$ se definió el cuarto sector identificado como área D. Las estructuras de área D son generalmente de pirca. La cerámica recuperada de la superficie de dicha área indica que ésta mantiene relación con el área A. Finalmente, en el extremo norte del sitio se identificó el área E. Esta dispone de estructuras de pirca y plataformas elevadas, asociadas a espacios vacíos, posiblemente plazas, desafortunadamente todas ya destruidas. En adición a estas cinco áreas, también se logró identificar un cementerio al extremo sur-oeste del sitio. La superficie general del sitio está cubierta de manera homogénea de cantos rodados que, originalmente, formaron parte de las estructuras, actualmente ya derrumbadas.

En seguida se procedió a determinar qué áreas del sitio eran contemporáneas y cuáles fueron establecidos con anterioridad, por ejemplo, a la llegada Inca. Por lo tanto, paralelo al mapeo del sitio se procedió a recuperar muestras de cerámica diagnóstica por separado para cada área. Este procedimiento permitió determinar, primero, que el área A pertenece al periodo Inca. Segundo, algunas áreas y unidades domésticas cuyas paredes estaban aún mejor conservadas pero que están fuera del área A (como son las áreas B, D, E) también pertenecen al periodo Inca, pues todas están asociadas a cerámica Inca en sus variaciones locales. Entretanto, una extensa porción del sitio (área C), con estructuras más deterioradas y como resultado difíciles de determinar su plan original, no presentan material Inca; en su lugar aparece una variedad de cerámica perteneciente al periodo Intermedio Temprano, identificado inicialmente por Rowe (1963: 11) como la 'tradición local.' Junto a dicho estilo local, hoy identificado como la tradición Huarato (Valdez 1998, 2009c), también ocurren algunos ejemplares de alfarería Nasca temprano (Valdez 2000b: Figura 2).

A su vez existen dos secciones de Tambo Viejo que no pertenecen ni al periodo Inca como tampoco al periodo Intermedio Temprano. El primero es un cementerio ubicado al lado sur-oeste del conjunto arqueológico y está relativamente separado del resto de los sectores con evidencias arquitectónicas. El segundo también es un pequeño cementerio establecido al extremo sur-este del área de habitación perteneciente al periodo Intermedio Temprano. Ambos cementerios tienen filiación con Wari, además de elementos derivados de Nasca tardío (Kent y Kowta 1994). De este modo, el conjunto arqueológico de Tambo Viejo presenta varias ocupaciones que en total representan aproximadamente 2000 años de ocupación.

Lo que se desprende de este esbozo bastante breve es que al momento de su llegada a Tambo Viejo, los oficiales Inca encontraron evidencias de un antiguo asentamiento. Pero, y al igual que los antiguos ocupantes del sitio, los Inca no tardaron en seleccionar este lugar para establecer su principal asentamiento, posiblemente por las diversas ventajas de orden estratégico que ofrece el lugar. Tal como se anotó, esta incluye su proximidad a los campos de cultivo y la amplia visibilidad sobre una extensa zona cultivable. Lo notable es que el Estado Inca prefirió establecer su principal establecimiento (área A) a un lado (sur-este) de las construcciones pertenecientes a la ocupación del periodo Intermedio Temprano. Una posibilidad para tal decisión parece haber sido evitar remover todo el escombro de las viejas estructuras ya destruidas. Desde luego, es posible que los Inca hayan re-utilizado el material de las viejas construcciones, proceso en el cual tal vez también contribuyeron en la destrucción de las estructuras que encontraron a su llegada. 


\section{Las Estructuras De Tambo Viejo}

Una vez definido la secuencia de la antigua ocupación humana de Tambo Viejo y considerando que el objetivo central de los trabajos en el sitio fue analizar su función dentro del esquema del Tawantinsuyo, quedaban importantes interrogantes que responder. Por ejemplo, era oportuno determinar qué encontraron los Inca al momento de su llegada al valle de Acarí. Para el caso específico del área A también fue preciso responder si fueron los Inca los directos responsables de la edificación de las varias estructuras allí presentes, o sólo hicieron las necesarias modificaciones y adiciones a un patrón ya establecido. Del mismo modo, fue de vital importancia determinar quiénes estaban en el valle al momento de la llegada de los Inca, cómo se diferenciaron ellos de los Inca, y qué cambios introdujeron los Inca a dicha población local. Y, por último, fue primordial saber si los Inca se acomodaron a los patrones locales, incorporando tal vez algunos elementos locales a su sistema en el mismo valle de Acarí y otras regiones fuera de Acarí.

Para ganar una mejor perspectiva de lo que fue Tambo Viejo durante la presencia Inca en el valle, se preparó un plano más detallado del área A, el sector administrativo Inca (Fig. 3). El plano, en combinación con los ejemplares de cerámica recuperados de la superficie, corrobora el origen Inca de las construcciones. La arquitectura en si es de pirca y constituye una evidencia muy pobre para determinar si estas con efectivamente construcciones del periodo Inca. Sin embargo, el diseño es en definitiva de origen Inca y es comparable a cualquier asentamiento Inca de la costa sur, especialmente con el del valle de Ingenio. De esta manera, la única interrogante pendiente a responder fue si los Incas encontraron estructuras locales que habrían sido destruidas para levantar las nuevas, o si las estructuras de las afueras del área central (como área D) eran de origen local. En la siguiente sección, se presenta una descripción más detallada de las construcciones identificadas como pertenecientes al periodo Inca.

\section{El centro administrativo}

El área A (Fig. 2), el más importante de Tambo Viejo, cubre en total un espacio de $360 \mathrm{~m}$ de norte a sur y 150 metros de este a oeste (Fig. 3). Las estructuras llegan por los lados sur y este hasta el escarpado, y todas están orientadas hacia el norte, donde se encuentra una amplia plaza (plaza 1) rectangular. El plano general de esta área es rectangular, pero modificado y adaptado al contorno natural del escarpado, en sus lados sur y este, respectivamente. El escarpado tiene una caída de 25 metros, aproximadamente, pero con una superficie plana. Demarcando el lado oeste aparece un muro largo que mantiene una orientación de norte a sur y sirve como límite de este sector. El coro de las estructuras del área A está constituido de cuartos de diversos tamaños, recintos y una pequeña plaza (plaza 2) que ocupa la sección central.

Una descripción más detallada del área A es complicado debido a la destrucción y la presencia de derrumbes de los muros caídos. La dificultad es todavía mayor al momento de definir los accesos de los diversos ambientes, precisamente porque las estructuras han sufrido derrumbes. Esta es una de las razones por las que sólo pocos accesos son ilustrados en la figura 3. Puesto que los muros han caído, también es difícil determinar la altura original de las construcciones. Tampoco tenemos una idea clara acerca del techo, aunque existe la posibilidad que fue de material perecedero. Batanes y sus respectivas partes activas ocurren sólo esporádicamente en este lugar, excepto la presencia de algunos cerca al horno, que es de origen colonial. Como se verá más adelante, este último es una buena evidencia de la reocupación de este sector durante el periodo colonial.

Además, en el área A fue difícil determinar la presencia de estructuras identificables como kancha (Rowe 1946: 223). Por lo menos en base al plano elaborado, es difícil afirmar que estructuras identificables como kancha hayan existido. Por el momento, y hasta que excavaciones sistemáticas se efectúen, queda también incierta la posible función de las varias construcciones allí presentes, aunque 


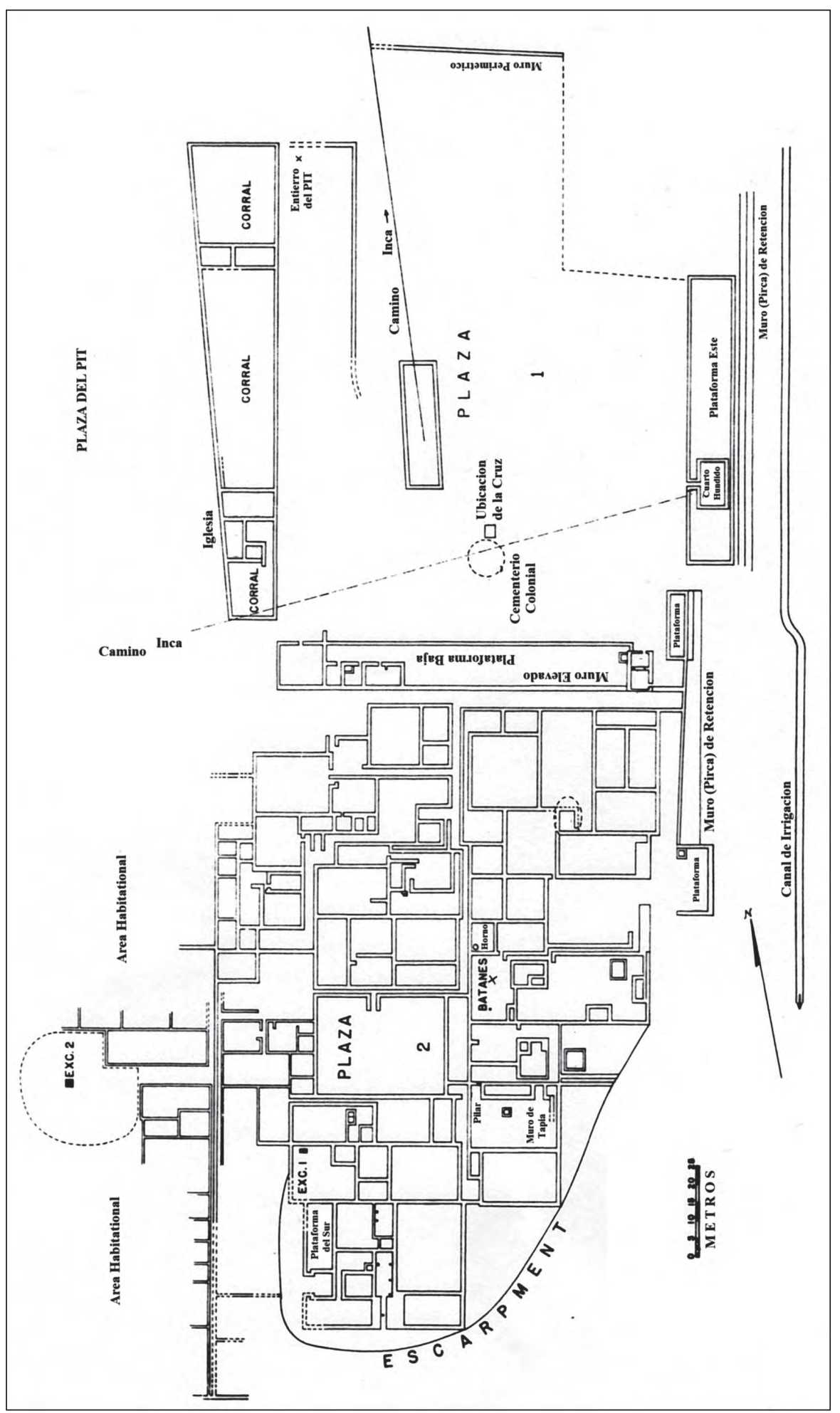

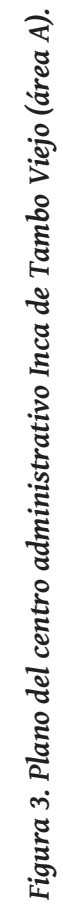


queda abierta la posibilidad que estas cumplieron una función distinta a los lugares de residencia ordinaria. Finalmente, los característicos nichos Inca no han sido identificados en el sitio, no obstante que algunas estructuras son lo suficientemente altos.

La plaza 1, y las estructuras a las que está asociada, está separada de las estructuras del lado sur por una amplia calle de $5 \mathrm{~m}$ de ancho, la misma que cruza toda la sección en una dirección de este a oeste. De este modo, la calle divide el sector en dos partes. La plaza 1 mide $160 \mathrm{~m}$ x $110 \mathrm{~m}$. Su lado norte está delimitado por un muro bajo que mantiene una orientación este - oeste, pero que no se extiende a lo largo de la plaza. La plaza es de superficie irregular, pero libre de piedras. A su lado este aparece una plataforma alargada de $5 \mathrm{~m}$ de altura (Fig 4), la misma que en su lado exterior dispone de tres muros de retención hechos de pirca que dan hacia el río. Los muros de retención tienen un largo de $80 \mathrm{~m}$ (Fig 5). Al lado sur de la plataforma y manteniendo una orientación hacia la plaza se observa un cuarto hundido, pero que cuyo piso mantiene el mismo nivel que la superficie de la plaza. El cuarto mide $10 \mathrm{~m}$ por $6 \mathrm{~m}$ de dimensión y tiene un acceso directo hacia la plaza 1.

Al lado sur de la plaza 1 aparece una plataforma baja de $10 \mathrm{~m}$ de ancho y mantiene una orientación de este a oeste. La cara sur de la plataforma, actualmente ya deteriorado, forma el límite este de la calle arriba mencionada. Este muro posiblemente alcanzó por lo menos $1 \mathrm{~m}$ de altura. Entretanto, inmediatamente al lado oeste de la plaza 1 aparece una estructura larga y de forma trapezoidal que mantiene una orientación de norte a sur. La estructura dispone de tres divisiones mayores y dos estructuras elevadas, cuyos muros alcanzan hasta $3 \mathrm{~m}$ de altura. Esta estructura fue construida de adobes y piedra, y como se discute más adelante ésta constituye una estructura colonial.

Si uno se detiene en la parte superior de la plataforma del lado este de la plaza 1 y observa $5^{\circ}$ Sur del oeste, se llega a percibir el camino Inca que ingresa del lado oeste, en línea directa, en dirección a la plaza 1 de Tambo Viejo. Para ser más precisos, el camino llega justo al ingreso del cuarto hundido de

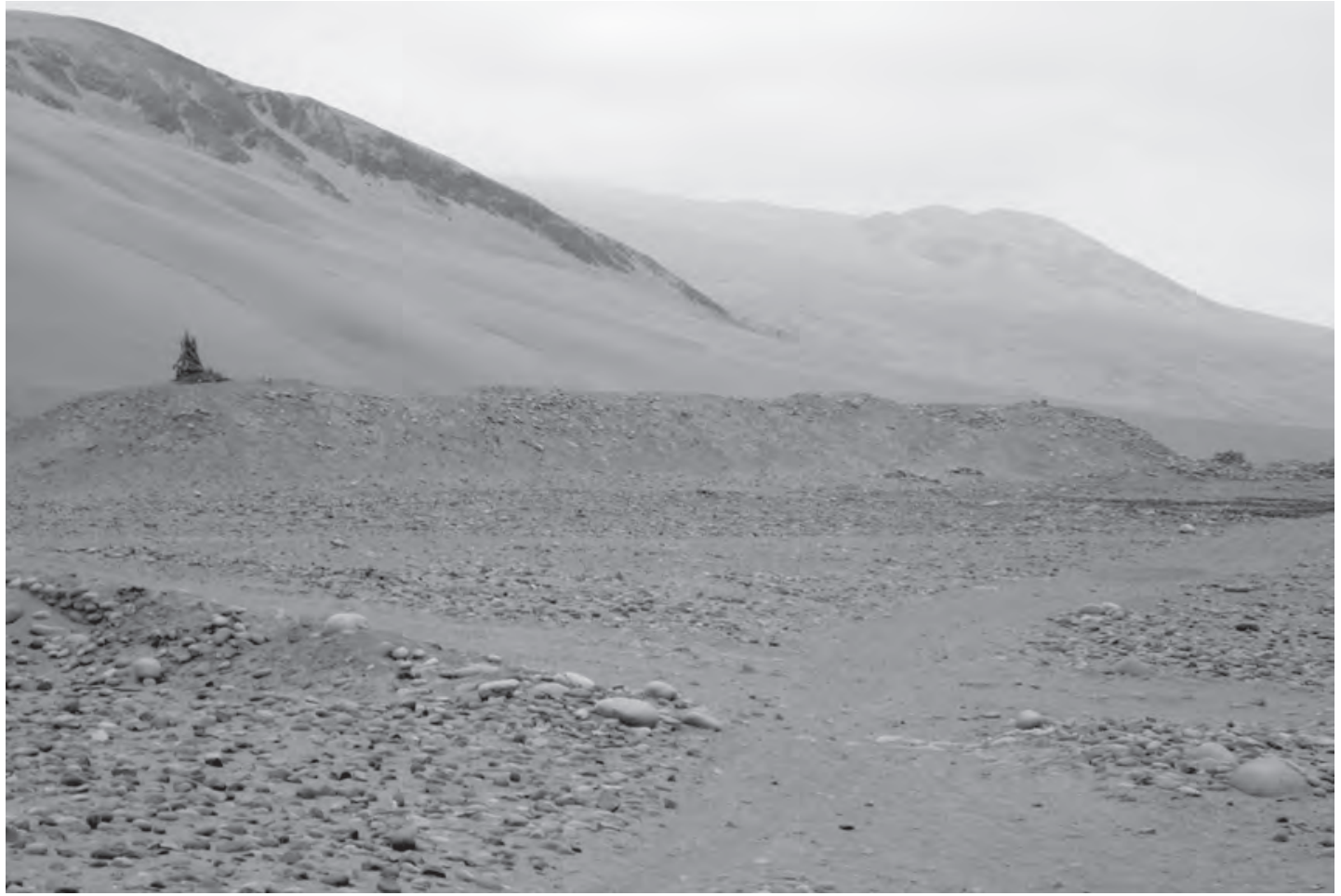

Figura 4. Plataforma del lado este de la Plaza 1. 


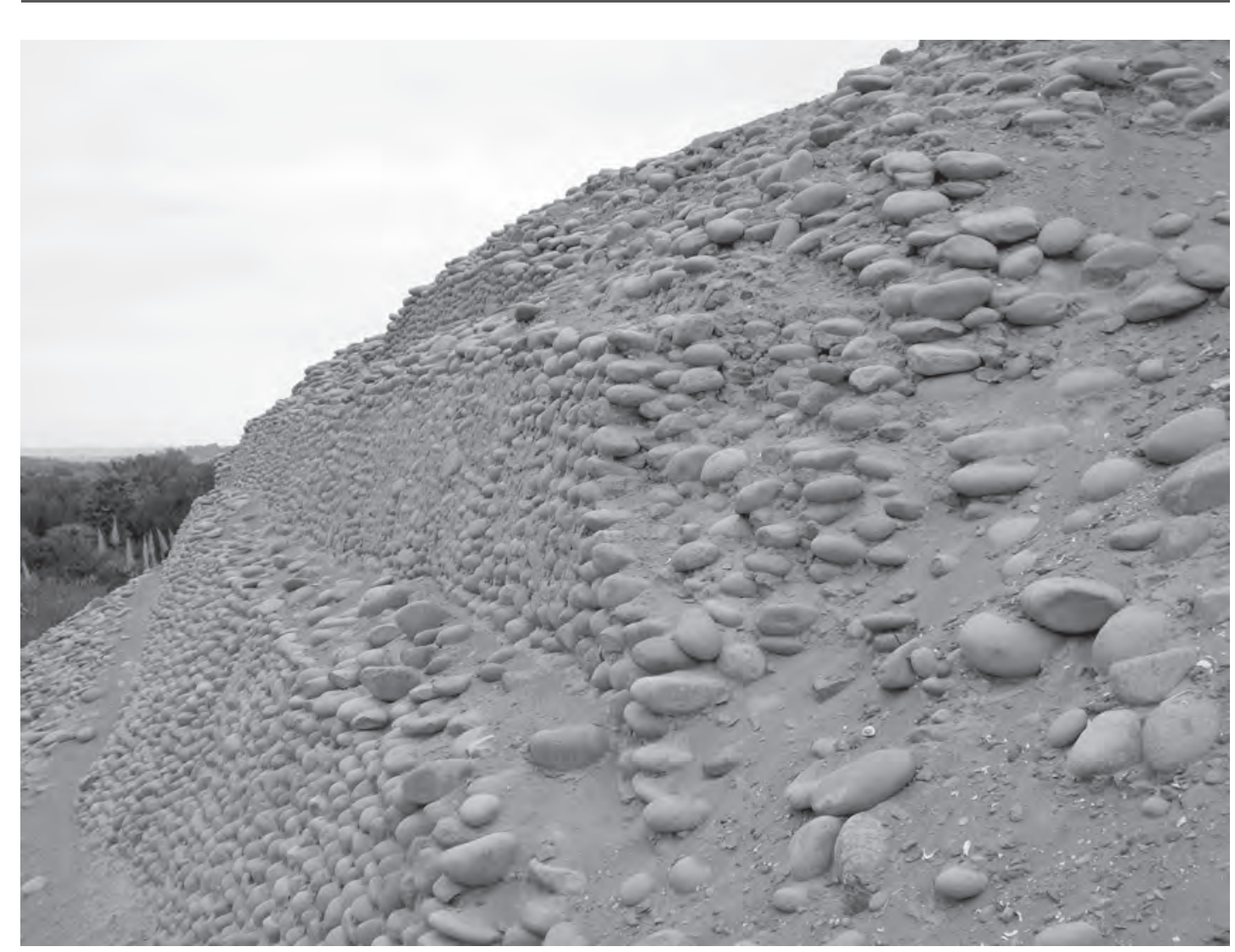

Figura 5. Muros de contención del lado este de la Plataforma del lado este de la Plaza 1.

la plataforma y sugiere que el camino parece que estaba diseñado para ingresar a dicho recinto. Con el transcurso de los años, el camino se ha hecho poco visible, especialmente cuando uno se encuentra sobre el mismo camino. Sin embargo, a la distancia, el camino es todavía observable. Medidas tomadas en varios puntos indican que el ancho del camino fue aproximadamente de $8 \mathrm{~m}$. Importante es anotar que la única estructura que obstaculiza el camino cuando este ingresa a la plaza 1 es la porción sur de la estructura trapezoidal ubicada inmediatamente al lado oeste de la plaza 1. Esto sugiere que dicha estructura fue establecida con posterioridad, es decir durante el periodo colonial.

A su vez existe un segundo camino que parte desde la plaza 1 en dirección norte y tiene un ancho que oscila entre 5 y $6 \mathrm{~m}$. Inmediatamente al norte de la plaza 1, el camino delimita físicamente la sección con ocupación Inca de la sección con ocupación perteneciente al periodo Intermedio Temprano (área C). Desafortunadamente, no se logró determinar la dirección total del camino, debido a la presencia del centro poblado de Acarí. Por cuanto, sitios como Lucasi y Otapara, ambos contemporáneos a Sahuacarí y el mismo Tambo Viejo, están ubicados en la sección superior del valle, existe la posibilidad que dichos asentamientos estaban conectados con Tambo Viejo. Por lo tanto, el camino en mención debió haber continuado a la parte alta del valle. Es también importante anotar que en 1954 las comunidades de la sierra inmediata al valle de Acarí aún descendían hasta Acarí transportando sus productos en caravanas de llamas (Fig 6) para el intercambio con productos del valle. De este modo, puede haber poca duda que este segundo camino llegó más allá de los límites de Tambo Viejo.

Las estructuras del centro principal de Tambo Viejo fueron construidas por lo general en base a cantos rodados y adobes, aunque los primeros fueron por excelencia los materiales de construcción 


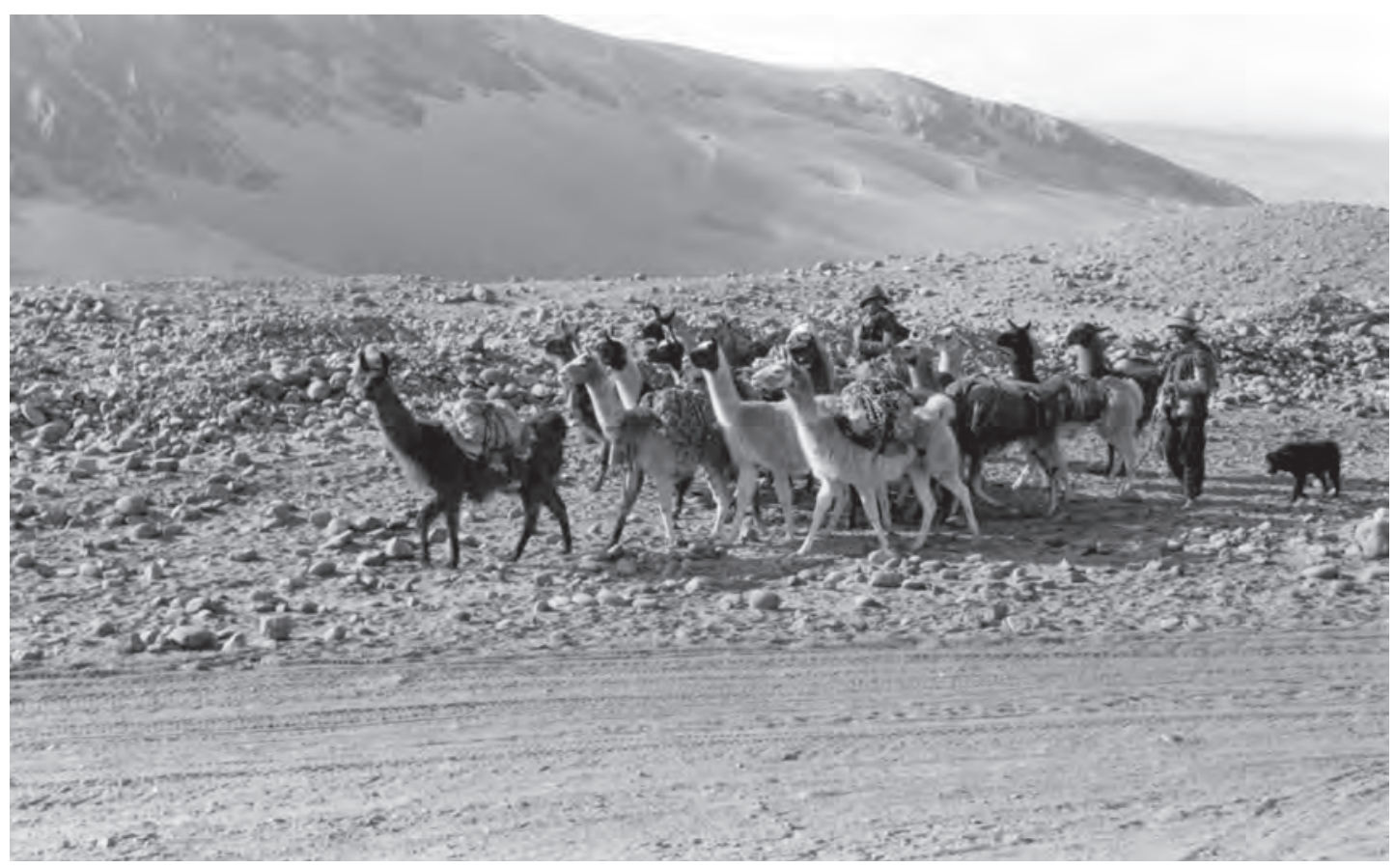

Figura 6. Caravana de llamas pasando por las inmediaciones de Tambo Viejo en marzo de 1954.

de preferencia por su abundancia en las proximidades del sitio. Los cantos rodados fueron sentados sobre argamasa y finalmente las paredes habían sido cubiertas con un enlucido también de barro. Este tipo de construcción es identificado como pirca. Mientras algunas estructuras fueron hechas exclusivamente de cantos rodados, en otras es observable que tanto cantos rodados como adobes fueron combinados (Fig 7). Los muros de las estructuras tienen un ancho de $50 \mathrm{~cm}$ y fueron levantadas de dos alineamientos de cantos rodados y/o adobes. Tal vez indicando una función distinta, los muros de algunas estructuras son poco más anchos.

Estructuras de adobes existen, pero son pocas. Por alguna razón, hay una mayor presencia de estructuras de adobes en el lado sur del área A y las estructuras del periodo colonial. Los adobes de Tambo Viejo son del mismo tipo que los adobes utilizados en otros sitios Inca de la costa, como Paredones, Ingenio, Tacaraca (Morris y von Hagen 2011: 148), Tambo Colorado (Gasparini y Magolies 1980: 124) y el mismo Pachacámac. Estos adobes son anchos y planos, relativamente largos y como tales bastante pesados (Fig 8). Sin embargo, no todos los adobes son del mismo tamaño; más bien, existe una variación, especialmente en cuanto al largo se refiere. Los muros hechos de adobe también utilizaron el barro. A diferencia de las pircas, una menor proporción de barro se había utilizado en los muros de adobe, esto debido a la superficie plana de los adobes. Los muros de adobe fueron igualmente enlucidos con una capa de barro. Oportuno es anotar que evidencias de pintura, y contrario a Tambo Colorado (Protzen 2006; Morris y von Hagen 2011: 142), no existen en Tambo Viejo. Una excepción es la estructura trapezoidal del lado oeste de la plaza 1 que como ya se anotó pertenece al periodo colonial.

Finalmente, en la sección sur-este del área principal de Tambo Viejo se detectó la presencia de un muro de tapia. Esta es la única evidencia del uso de tapia en todo Tambo Viejo. Si existen otras construcciones similares solo será posible determinar con futuros trabajos de excavación, pues existe la posibilidad que otros muros de tapia tal vez estén bajo los escombros de los muros derrumbados. 


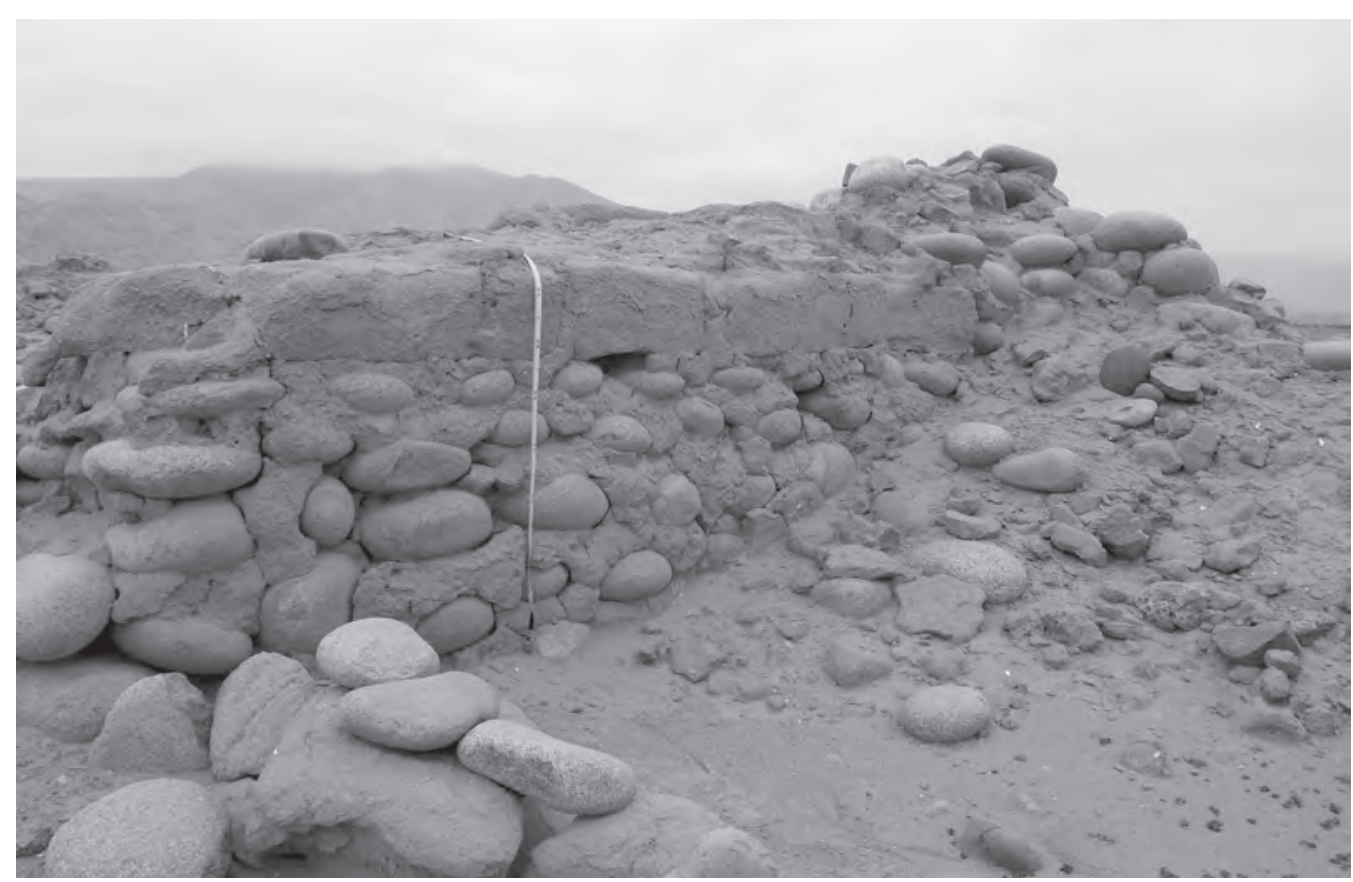

Figura 7. Estructura del área A de Tambo Viejo construido de cantos rodados y adobes.

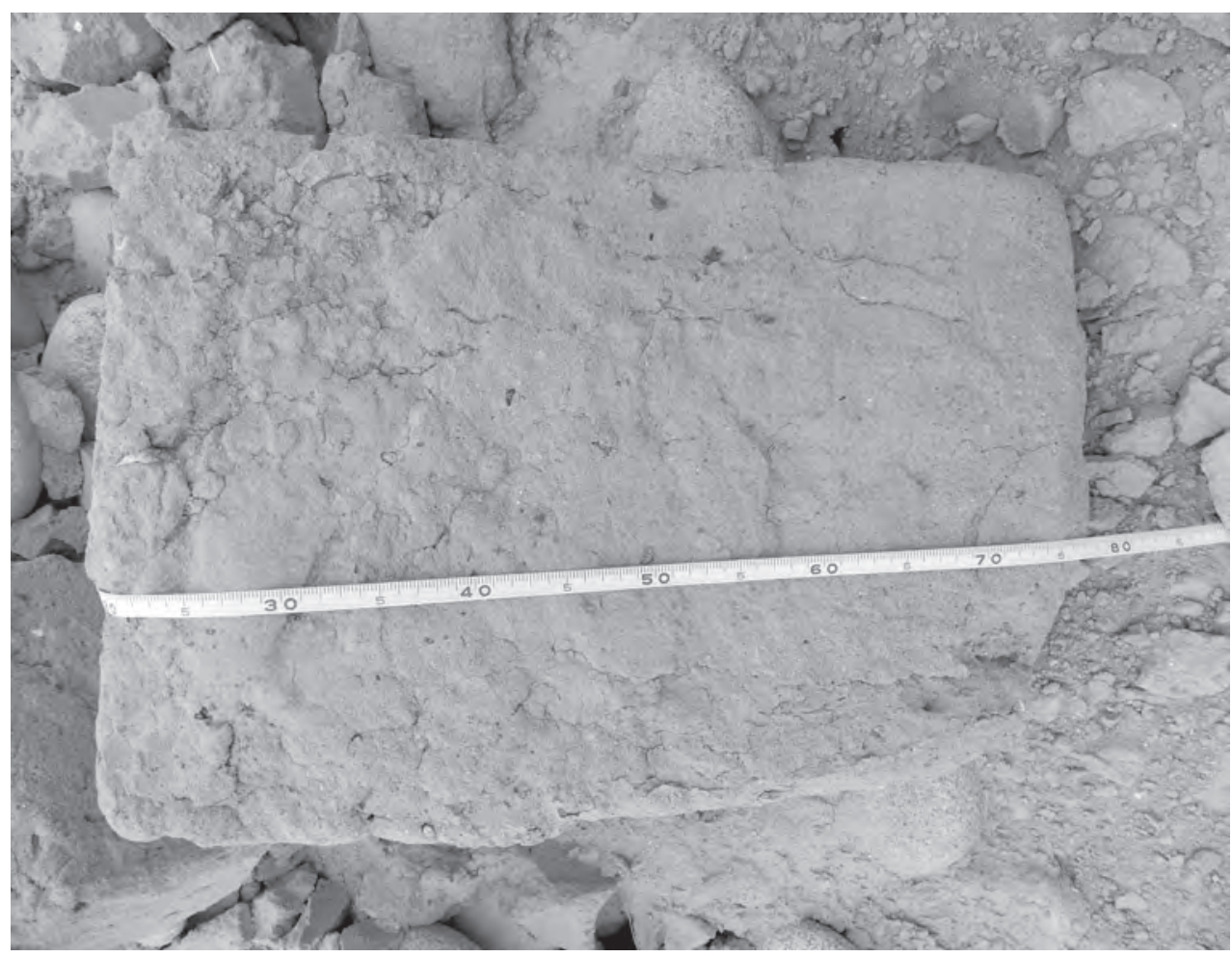

Figura 8. Adobe utilizado en las construcciones del área A de Tambo Viejo. 


\section{Las estructuras residenciales Inca}

Fuera de los límites del área principal de Tambo Viejo arriba descrito aparecen pequeñas unidades de construcción, recintos, y plataformas también establecidas por los Inca y que cumplieron diversas funciones. Algunas de éstas constituyeron las áreas de habitación. En total se ha podido identificar 4 áreas de habitación. El primero (área B) se encuentra al lado oeste del área A y es la más pequeña de todas. Una segunda (área D) se encuentra precisamente al norte de la plaza 1 y al lado este del área $C$ (Fig 9). Esta es la más extensa y está conectada a la plaza 1 mediante un camino que sale de la plaza en dirección norte. Un tercer lugar con estructuras residenciales aparece ocupando la sección sur-este del área C. Esta es bastante pequeña y posiblemente representa una de las últimas construcciones Inca previa a la llegada de los españoles. Finalmente, estructuras residenciales establecidas en tiempos Inca se encuentran en la sección norte del sitio (área E), precisamente al norte del área C. Allí es también observable la presencia de plazas, corrales, plataformas, así como los depósitos. De todas las áreas residenciales, aquella ubicada al norte de la plaza 1 (área D) es la más extensa y posiblemente también la más importante. Tal vez indicando dicha particularidad, área $\mathrm{D}$ también dispone de una plaza en su sección norte (plaza 4, Figura 2).

La identificación de estas áreas como pertenecientes al periodo Inca está basada en la presencia de cerámica del mismo estilo que en el área principal Inca de Tambo Viejo (área A). La única diferencia es que la mayoría de la cerámica no es decorada. Además, las varias estructuras en dichas áreas habían sido construidas en partes y sin seguir un plano previamente elaborado. Como resultado, la configuración de las varias estructuras es irregular y de este modo son fácilmente diferenciables de

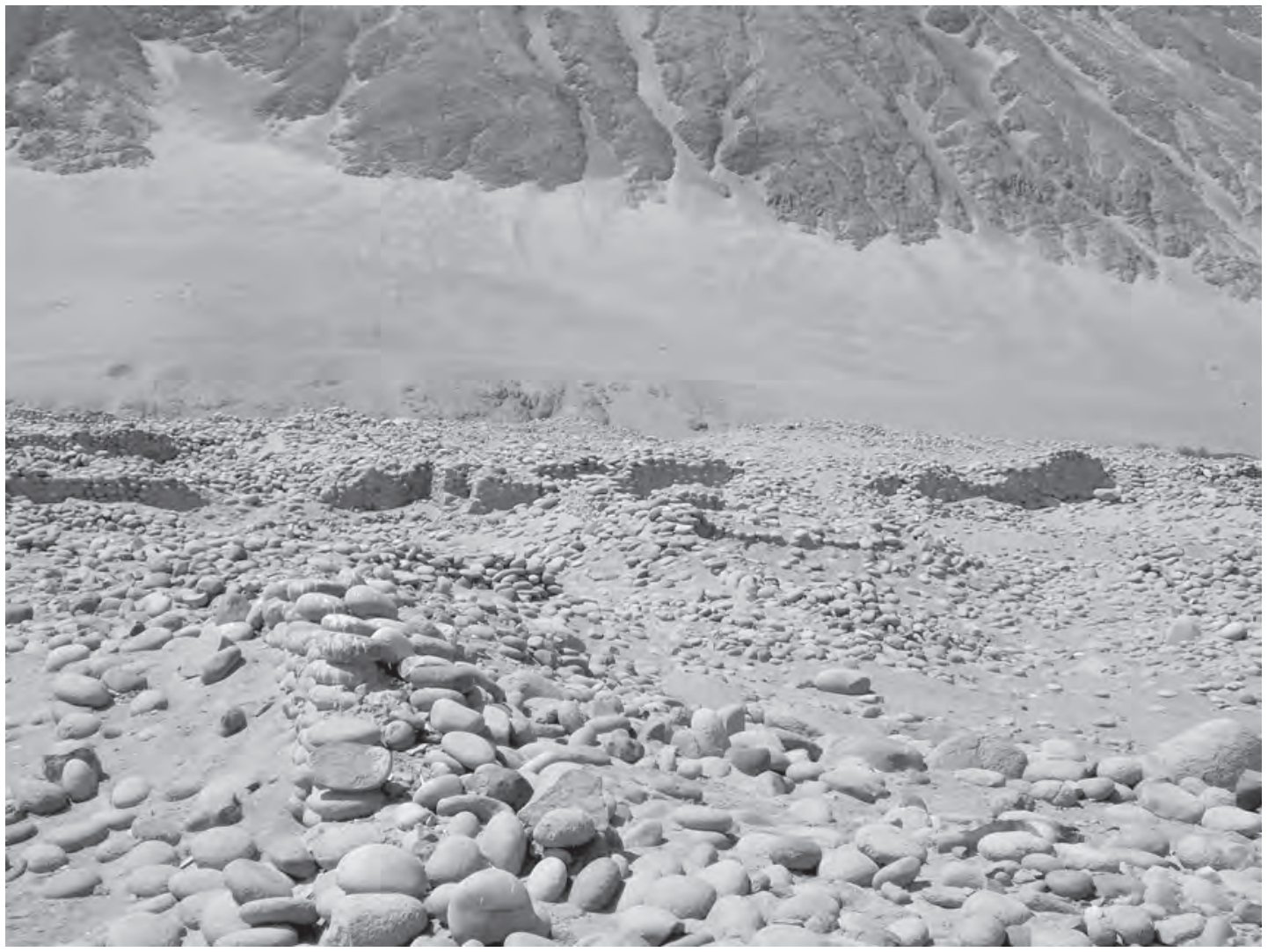

Figura 9. Estructuras del área D de Tambo Viejo. 
las estructuras del área A, contrariamente edificadas en bloque. Junto a la alfarería Inca, ocasionalmente también ocurre la cerámica colonial, especialmente una de engobe crema.

Para ganar una mejor perspectiva de las estructuras residenciales, se llegó a elaborar planos de secciones específicas. En primer lugar, dicho plano (Fig 10) demuestra la irregularidad de las estructuras. En segundo lugar, el plano revela un patrón básico, la misma que consiste de pequeños cuartos asociados a un patio. En general, ésta organización corresponde perfectamente con el patrón Inca bastante conocido como kancha (Gasparini y Margolies 1980: 181).

Para ilustrar mejor a las estructuras residenciales, se prestó atención particular a un recinto del lado sur de área C que dispone de un patio (o kancha) algo cuadrado (Fig 10). En su extremo sur-este aparece un cuarto pequeño, pero elevado. Al lado oeste de dicho cuarto aparece otro ambiente, de forma rectangular, que está dividido por un alineamiento de piedras. La sud-división del lado sur está asociada a una estructura semi-circular hecha de piedra, construida exactamente en la esquina suroeste, que tal vez haya funcionado a modo de depósito; la otra mitad de esta estructura tenía el piso casi limpio y dispone de un acceso en su lado nor-oeste.

Todo el recinto había sido construido por lo general de pirca, siguiendo los mismos patrones de construcción observados en el centro principal de Tambo Viejo. En ningún caso se pudo observar muros más altos que un metro; en base a las piedras caídas observadas en las inmediaciones de los muros se puede estimar que éstos no fueron tan altos. En general, el recinto no parece haber sido substancialmente disturbado y como tal es un buen indicador de cómo eran las estructuras habitacionales de Tambo Viejo. De todos, destaca el cuarto elevado que estaba a un metro por encima del piso del resto del recinto, pero sus muros estaban del todo caídos. La ocurrencia de este cuarto elevado es un patrón que se repite en el resto de las estructuras residenciales Inca de Tambo Viejo, la misma que también fue observada en Chala. En base a la observación hecha por Gasparini y Margolies (1980: 133), más su ocurrencia repetida en Tambo Viejo, es posible que los cuartos elevados fueron los lugares donde sus habitantes durmieron.

Paralelo al muro este del recinto, en la parte exterior, se hallaron hoyos cuadrangulares de un metro de diámetro y un metro de profundidad. Los hoyos tienen una pared de pirca y posiblemente fueron estructuras destinadas para depositar productos. Entretanto, un batán aparece en la esquina noreste del patio, mientras que otro batán fue observado detrás del cuarto elevado. Es de destacar que tanto las estructuras cuadrangulares con pared de pirca, como los batanes (Fig 11), siempre aparecen asociadas a estructuras habitacionales; en particular, los batanes ocurren en todos los patios e indica que fueron elementos primordiales de las estructuras que cumplieron una función doméstica. En efecto, Cobo (1956[1653]: 243; Rowe 1946: 221) es bastante específico al anotar acerca de la importancia de los batanes.

Si se hace una comparación de este recinto con otro del área D (Fig 12), se puede percibir mejor el patrón desorganizado del área D. Como en el caso anterior, los muros también están derrumbados y en algunos casos sólo es posible observar sus cimientos. En consecuencia, se hace difícil determinar no sólo los accesos de las estructuras, sino también la asociación de cuartos con patios específicos. No obstante dicha dificultad, una atención a la esquina de los muros permitió determinar que los varios recintos que conforman las áreas habitacionales fueron construidas independientemente (Fig 13); fue el conjunto de tales construcciones que creó todo un laberinto que precisamente es el área D. Sin embargo, resalta la ocurrencia repetida de cuartos elevados, depósitos y batanes en todo el sitio. Así como todavía ocurre en las viviendas rurales de la sierra central del Perú, parece que fue una norma disponer por lo menos de un batán en cada recinto. Su ausencia en algunos casos, por lo tanto, debe obedecer a que al parecer fueron posteriormente retirados para ser reutilizados en algún otro lugar. La aparente poca ocurrencia de la parte activa de los batanes posiblemente también obedece al mismo hecho.

A diferencia del área principal Inca de Tambo Viejo, los adobes fueron utilizados solo ocasionalmente en la edificación de las estructuras residenciales. El principal material de construcción fueron 


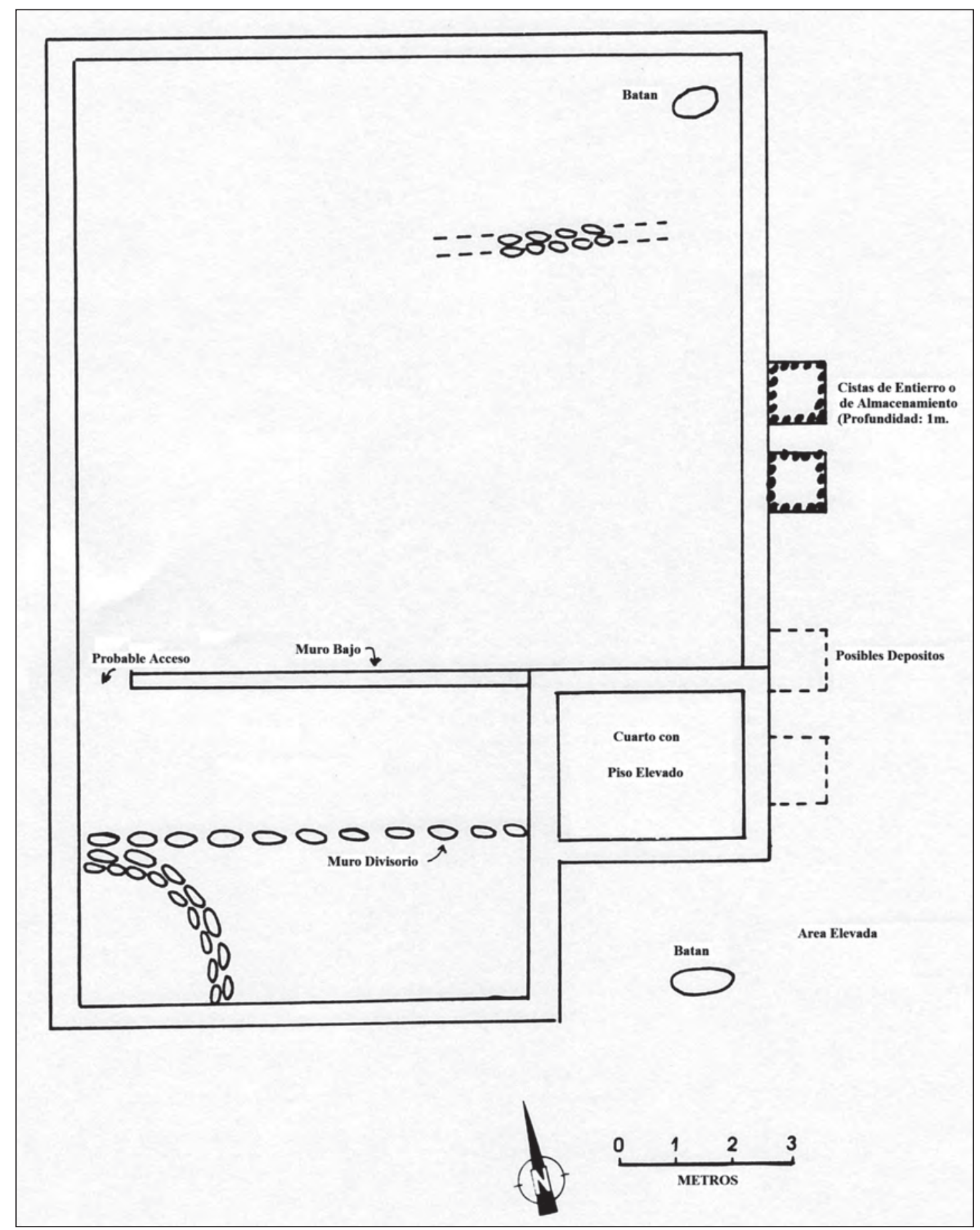

Figura 10. Plano de un sector habitacional Inca del área $C$. 


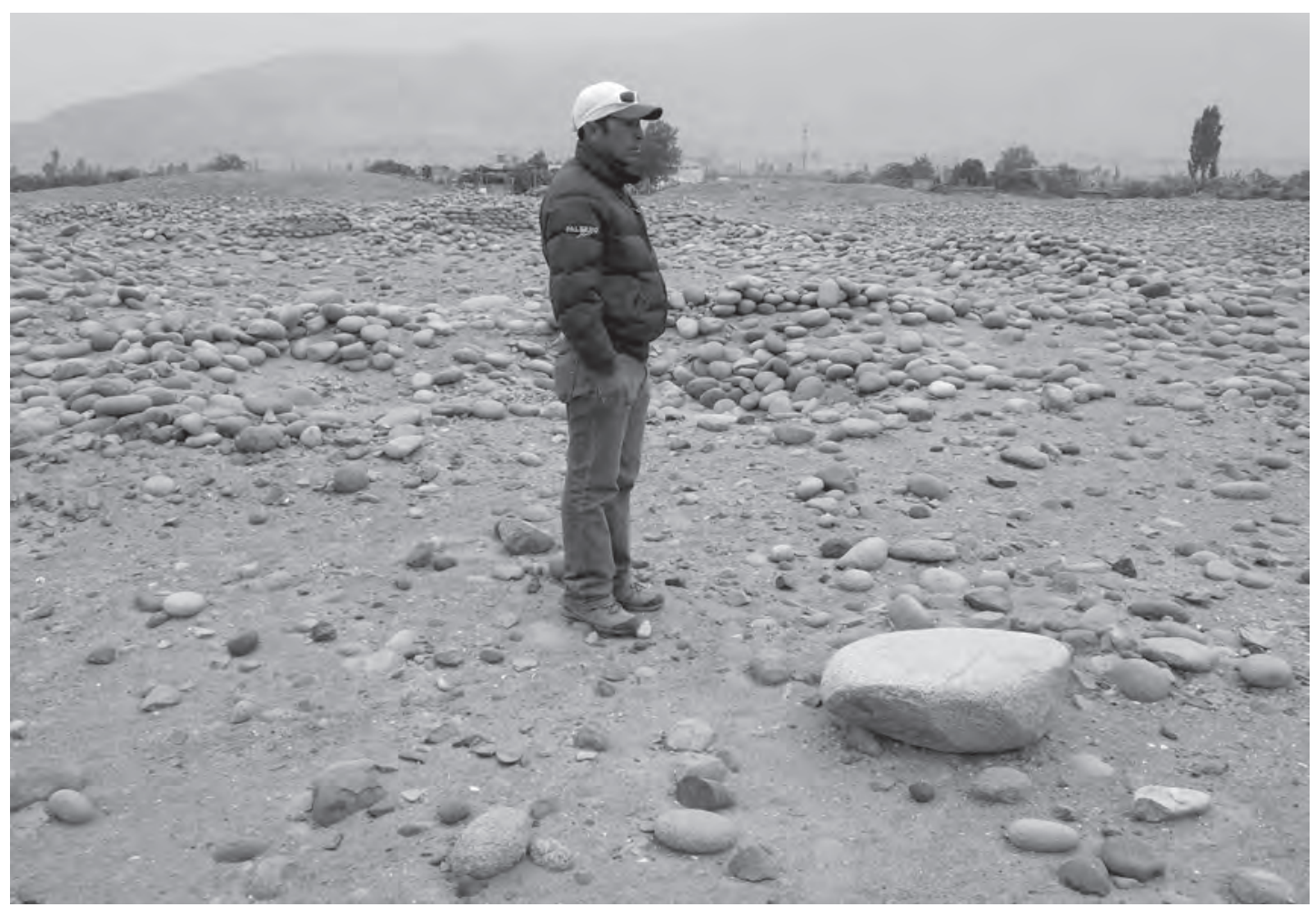

Figura 11. Batán asociado a uno de los patios del área $C$.

los cantos rodados y los muros fueron revestidos con un enlucido de barro. A su vez, la ausencia de postes en asociación a los muros no permite sugerir que parte de las construcciones de Tambo Viejo hayan sido de quincha. En efecto, en otros sitios contemporáneos a Tambo Viejo, como Otapara y Sahuacarí, tampoco se ha observado la presencia de estructuras de quincha. Por ejemplo, todas las estructuras de Sahuacarí fueron hechas de pirca. Algo similar parece que se dio en Tambo Viejo, aunque es difícil negar el uso de la quincha en su totalidad sin antes llevar adelante trabajos sistemáticos.

Considerando que el área D de Tambo Viejo es la más extensa y compuesta por una mayor cantidad de estructuras, existe la posibilidad que éste fue la sección principal de habitación Inca. Tal como se anotó líneas adelante, esta sección dispone de una amplia plaza y está asociada a un camino que lo conecta con el área principal de Tambo Viejo. Al lado de área D, el resto de las áreas habitacionales probablemente constituyen suburbios, establecidos con posterioridad, tal vez cuando el área D llegó a ser colmado en su integridad.

\section{Los depósitos de Tambo Viejo}

El área E de Tambo Viejo presenta también sus propias problemas. Aquí existen recintos similares a los previamente mencionados, aunque por lo general son distintos. En total, hay 4 grupos de estructuras en esta área. El segundo del norte está compuesto de corrales, pero que cuyos muros habían caído en su gran mayoría. La superficie de los corrales aparece limpia, haciendo difícil determinar la exacta función de tales estructuras. Fragmentos de cerámica ocurren y son del mismo tipo que las encontradas en el área principal Inca de Tambo Viejo. La única diferencia es que la mayoría no son decoradas o diagnósticas. Todo esto confirma que estas estructuras son de tiempos Inca. Desafortunadamente, todas estas estructuras han sido del todo destruidas; en la actualidad en 


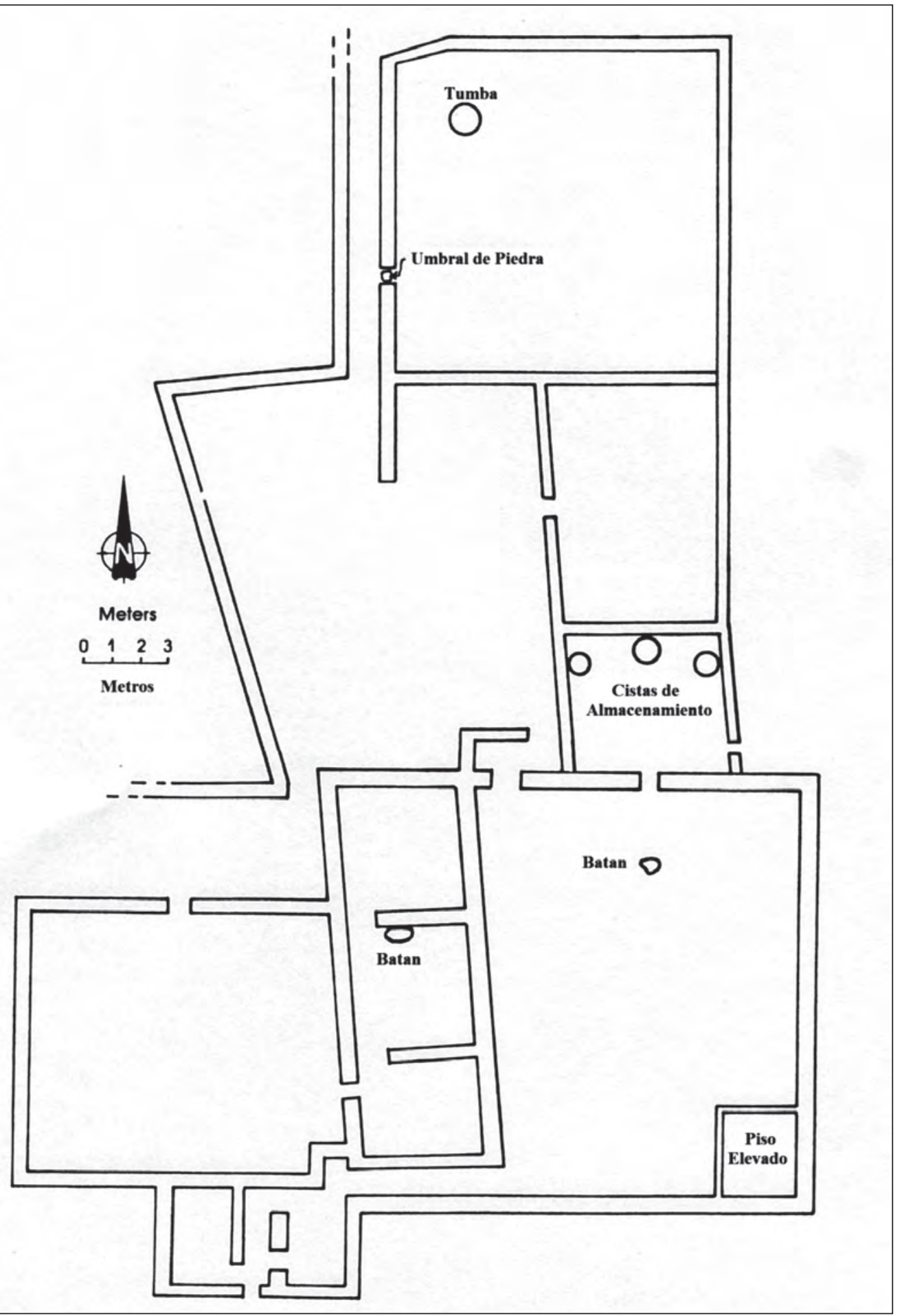

Figura 12. Plano de un sector habitacional Inca del área D. 


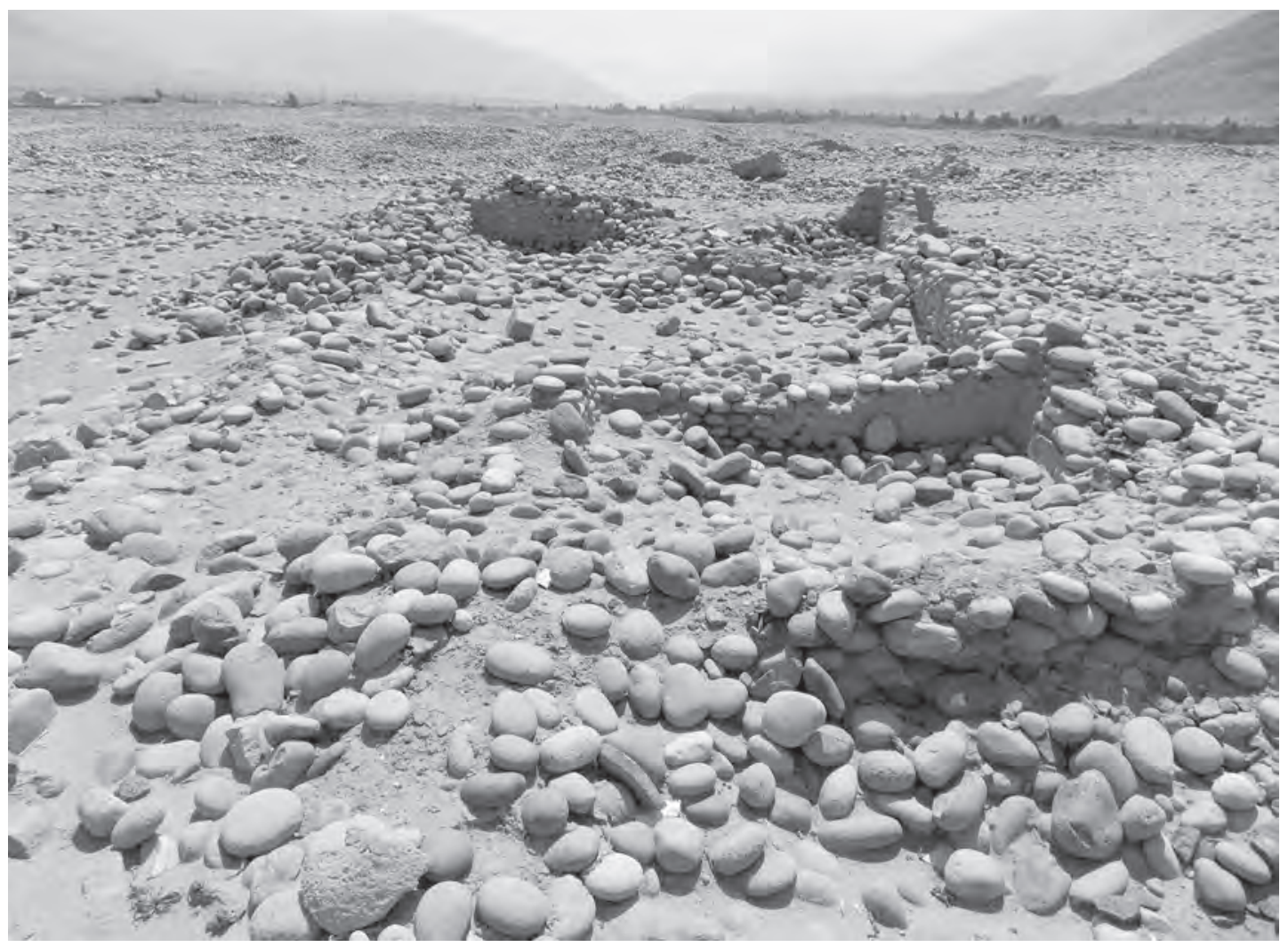

Figura 13. Estructuras residenciales del área D.

esta área aparecen numerosas estructuras contemporáneas, incluido las instalaciones de un centro educativo secundario.

En su configuración general, el área E, especialmente con sus recintos de muros bajos y pisos planos, guarda mucho parecido con el sitio de Chala Viejo, de la quebrada de Chala, que fue establecido a inicios del periodo colonial. Los materiales de superficie también permiten afirmar que su ocupación es predominantemente colonial. Sin embargo, Chala Viejo y Tambo Viejo no son idénticos, no obstante que ambos disponen de estructuras similares. Además, para ambos sitios se ha notada el uso limitado de los adobes. Las semejanzas y las diferencias entre ambos sitios abre la interrogante que si las estructuras de Chala Viejo son en su totalidad del periodo colonial o que, por lo menos algunas, ya existían durante el periodo Inca. Considerando que el área E de Tambo Viejo guarda mucho parecido con Chala Viejo y que el área E es también diferente del resto de las estructuras Inca del mismo Tambo Viejo en general, es posible que por lo menos una mitad de las estructuras de la sección norte de Tambo Viejo hayan sido establecidos durante el periodo colonial.

Sin embargo, entre las varias estructuras de dicho sector resalta la presencia de los depósitos Inca (Valdez 1996). Siguiendo la expansión del poblado de Acarí a la sección norte de Tambo Viejo, en 1990 se efectuó un trabajo de rescate, especialmente de las estructuras identificadas inicialmente como los depósitos Inca. En primer lugar se expuso una larga plataforma rectangular que mantenía una orientación de este a oeste (Fig 14). La plataforma es una construcción artificial levantada en base a cantos rodados. Sobre dicha elevación, que tiene una altura que supera un metro, se detectaron un total de 3 recintos rectangulares y 2 ambientes más pequeños, ubicadas en una sección intermedia entre las estructuras anteriores. El pequeño ambiente del lado este estaba sub-dividido en 2 secciones, siendo 


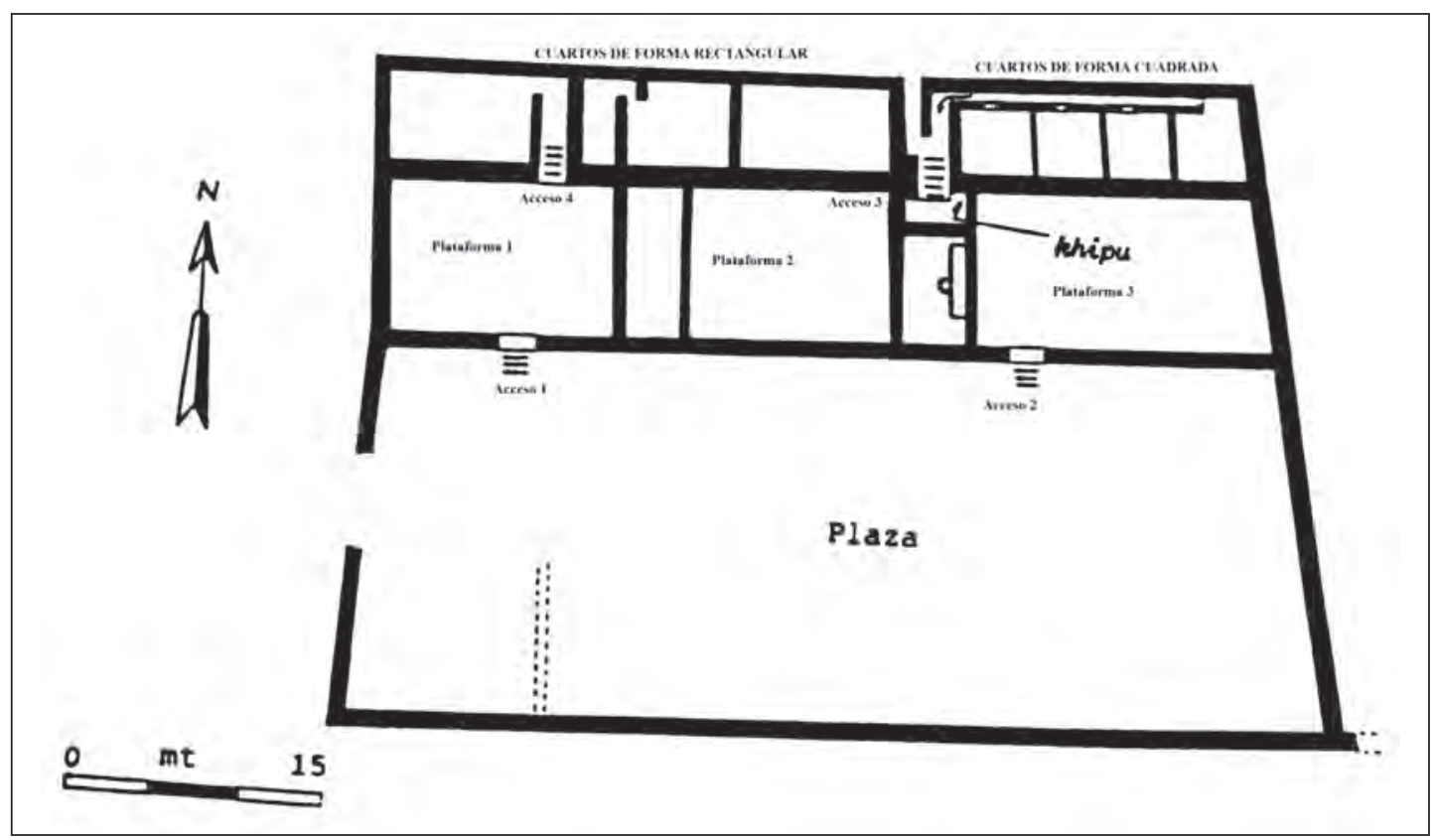

Figura 14: Dibujo de planta de los depósitos Inca de Tambo Viejo.

más grande la parte del lado sur. En esta última, y adosado al muro del lado este, había una banqueta construida de piedras y barro; frente a dicha banqueta se ubicó un pequeño semi-círculo con paredes y barro, y que estaba sellada con una laja redonda. Al retirar la laja se halló una deposición de cascajo limpio traído desde el río. Desafortunadamente, queda incierta la función de este hallazgo, así como el de los varios recintos hallados sobre la plataforma.

Al lado sur de la plataforma aparece una larga plaza rectangular, paralela a la plataforma, y cuyos muros habían también sido construidas de pirca. En la esquina nor-este de la plaza se llegó a definir un muro que alcanzaba los $2 \mathrm{~m}$ de altura y sugiere que todo el muro de la plaza posiblemente alcanzó dicha altura. De la plaza hay dos pequeñas escalinatas que dan acceso a dos de los recintos establecidos sobre la plataforma. Las escalinatas también habían sido construidas de cantos rodados y barro.

Por último, al lado norte de la plataforma, pero siempre adosado a éste, se llegó a exponer dos grupos de cuartos pequeños. Los tres primeros cuartos del lado oeste son rectangulares, mientras que los cuartos del lado este son cuadrangulares. El cuarto rectangular del extremo oeste dispone de una escalinata que da acceso a la plataforma. A su vez, los 4 cuartos cuadrados tienen sus pequeños accesos orientados hacia el norte y todos conectados a un pasadizo angosto que mantiene una orientación de este a oeste. En su lado oeste, el pasadizo está conectado a una escalinata que se da acceso a la plataforma. Precisamente en la sección superior de la escalinata se halló un khipu, confirmando el origen Inca de las estructuras aquí referidas. Varios aspectos de los cuartos del lado norte de la plataforma, discutidas en más detalle por Valdez (1996: 40-41), han confirmado que éstas fueron los depósitos Inca. Sin embargo, puesto que las estructuras fueron halladas vacías, queda incierto el tipo de producto (o productos) allí depositados. Desafortunadamente, todas estas estructuras han sido del todo destruidas en la actualidad como resultado de la expansión del poblado de Acarí.

Es oportuno anotar que estructuras similares a los depósitos de Tambo Viejo también han sido identificados en otros sitios Inca de la costa sur. Por ejemplo, en el sitio de La Caleta de la quebrada de Chala y conectado al igual que Tambo Viejo al camino Inca, existen estructuras rectangulares aso- 
ciadas a un espacio abierto. Del mismo modo, en el sitio de Quebrada de la Vaca (hoy Tambo Inca), existen estructuras similares utilizadas como depósitos. Dichas estructuras fueron construidas de forma idéntica y sus tamaños son muy homogéneos, lo que indica que las semejanzas no son simples coincidencias, sino intencionales, orientados posiblemente a facilitar la contabilidad de los productos depositados (D’Altroy y Earle 1992: 190). De este modo, el hallazgo del khipu en asociación a las estructuras de Tambo Viejo tampoco es un simple accidente (ver, Murra 1983: 185).

Por el norte, en el valle de Ingenio, hay otro sitio Inca que cuenta de estructuras similares a las mencionadas líneas adelante. En este caso, los depósitos se encuentran en una parte elevada y alejados del centro administrativo. En asociación a los depósitos de Ingenio se ha llegado a observar fragmentos de grandes vasijas de cerámica Inca. Las vasijas posiblemente formaron parte de los sistemas de almacenamiento.

La presencia repetitiva de estructuras similares asociadas a centros Inca conectados al camino real Inca, como Ingenio, Tambo Viejo y La Caleta, indica que establecer los depósitos a lo largo del camino Inca fue un aspecto importante dentro del sistema del Tawantinsuyo. Entretanto, es notable la diferencia con otros sitios Inca que no cumplieron la función de Tambos y por lo tanto no están directamente asociados al camino Inca. Este es el caso de Quebrada de la Vaca, sitio que no cumplió la función de tambo. En Quebrada de la Vaca los depósitos Inca son más numerosos y diferentes de los cuartos pequeños observados en La Caleta y Tambo Viejo. En última instancia, la ubicación de los depósitos en los tambos formó parte de la estrategia Inca que facilito la movilización rápida y eficiente de los productos (Murra 1983: 179).

Sería por demás beneficioso verificar si otros tambos de la costa también comparten los patrones observados en los tambos de La Caleta, Tambo Viejo e Ingenio. En estos tres tambos, los depósitos están ubicados a cierta distancia del centro principal. Por supuesto, esto no es una tarea fácil considerando que encontrar sitios Inca bien conservados es complicado. La situación por lo general es como el de Paredones en Nasca, donde una gran sección del sitio ha sido destruido al tiempo que nuevos campos agrícolas fueron establecidos. Cuando esto ocurre es imposible recatar el plan original de un sitio. Para el caso de Paredones, Cieza (1973: 185) informa de la existencia de depósitos; dicha versión es la única evidencia del que se dispone, pero no existe forma alguna de verificarlos arqueológicamente.

De lo aquí anotado, es evidente que las estructuras Inca de Tambo Viejo son la mejor expresión del tipo de construcción identificado por Hyslop (1990: 244) como una mezcla entre Inca y local. En algunos casos, las estructuras fueron levantadas siguiendo un diseño Inca, pero los arquitectos fueron al parecer locales. En otros casos, tanto el diseño, como los constructores fueron definitivamente locales. Esta fuerte influencia local en Tambo Viejo obedece al corto tiempo de duración de la ocupación Inca que no logró asimilar por completo a la tradición local. Este aspecto también se manifiesta en la cerámica manufacturada durante este tiempo en el valle de Acarí.

\section{Estructuras coloniales}

En el curso de los trabajos de investigación en Tambo Viejo, se hizo evidente la existencia de una ocupación colonial. Esto creó un dilema difícil de resolver, pues era importante determinar el grado de alteración causada por la ocupación colonial sobre el centro administrativo Inca. La limpieza parcial de una estructura circular eventualmente permitió determinar la presencia de un horno construido al interior del centro principal Inca (Fig 15). Una acumulación de carbón y ceniza, asociados a un piso, indican que el horno fue utilizado con cierta intensidad. A su vez, y como ya se anotó líneas adelante, logramos determinar que una estructura rectangular había sido construida al lado oeste de la plaza 1, obstruyendo el camino Inca que ingresa a dicha plaza. Esta evidencia, en adición a la presencia de cerámica colonial, entre otros, indica que algunas de las estructuras del área central de Tambo Viejo son construcciones coloniales. 


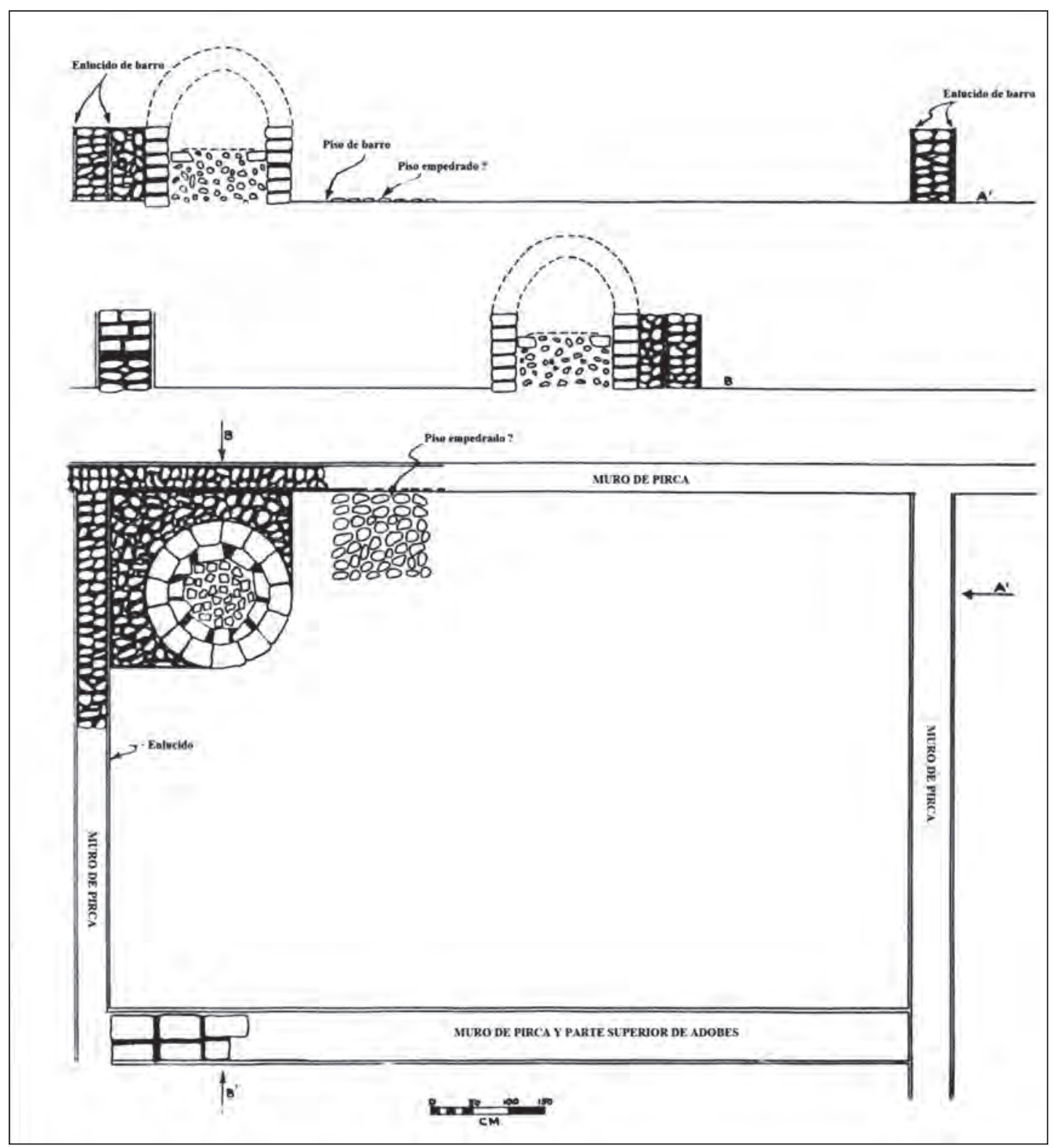

Figura 15: Horno construido en Tambo Viejo durante la ocupación colonial.

La siguiente interrogante fue diferenciar qué estructuras del sitio fueron edificadas durante la época colonial. Mientras se venían efectuando los trabajos en Tambo Viejo, algunos vecinos llegaron hasta el sitio a extraer adobes de las antiguas construcciones para preparar barro y elaborar nuevos adobes. Al hacer esto expusieron cerámica colonial en la parte superior de la estructura ubicada inmediatamente al lado oeste de la plaza 1, abriendo la posibilidad que esta estructura es de tiempos coloniales. Al mismo tiempo, se logró observar que la porción norte de esta estructura no mantenía alineación alguna con la estructura del lado este de la plaza, que es una plataforma elevada que no sólo es más larga, sino también más alta. Además, la plataforma dispone de un muro de retención de pirca y un cuarto hundido en uno de sus lados. A diferencia de la estructura del lado 
oeste de la plaza 1, restos coloniales no se hallaron en asociación a la plataforma, sugiriendo su origen Inca. De este modo, en ambos lados de la plaza 1 tenemos una plataforma de origen Inca y otra de origen colonial.

Paralelamente, observamos que los huaqueros habían excavado entierros en las inmediaciones de la estructura del lado sur de la plaza 1. Los entierros habían sido abandonados, al parecer porque no había objetos de valor asociados a los muertos. Una limpieza rápida reveló que éste se trata de un entierro colonial, al parecer un entierro masivo tal vez de las victimas de alguna epidemia y depositados a una profundidad de apenas 1,5 m. Una identificación en el mismo campo reveló que entre los muertos están individuos (8 en total) de todas las edades y de ambos sexos. Confirmando su origen colonial, en la parte central y encima de los muertos se halló una cruz de madera, también enterrada. Los individuos aquí enterrados fueron nativos y sus restos estaban en un excelente estado de conservación.

Con posterioridad, John H. Rowe, quien visitó el sitio mientras se venían efectuando los trabajos (ver Rowe 1956), anotó que la estructura del lado oeste de la plaza 1 debió haber sido la iglesia construida al momento de la ocupación colonial. Rowe también anotó que los españoles acostumbraron levantar sus iglesias inmediato a la plaza principal de los asentamientos y que en tiempos coloniales las gentes fueron enterradas directamente al frente de la iglesia. Por lo tanto, las modificaciones introducidas por los españoles al plan original del establecimiento Inca fueron considerables. Este hecho dificulta en cierta medida producir una descripción precisa del asentamiento Inca. El plan general del establecimiento Inca y el carácter de su simetría definitivamente representa un esquema Inca; sin embargo, los detalles de lo que dicho establecimiento fue originalmente es difícil de precisar sin antes efectuar mayores trabajos.

De lo mencionado en las secciones anteriores, queda manifiesto que en Tambo Viejo existen evidencias de constantes actividades de reconstrucción. Las reconstrucciones más obvias tomaron lugar durante la ocupación colonial, cuando nuevas estructuras fueron establecidas y otras ocupadas y eventualmente también reconstruidas. En primer lugar está el caso del horno establecida más o menos en la sección central del lado sur del antiguo centro administrativo Inca. El horno fue establecido al interior de una antigua estructura Inca. Primero, el horno había sido construido de adobes y estaba dotado de un piso compacto de arcilla. Posteriormente, el horno fue reconstruido cuando un nuevo piso fue construido sellando una acumulación de carbón y ceniza. Al tiempo que el horno fue reconstruido, había sido necesario levantar un muro de contención de forma cuadrada, posiblemente porque el horno fue debilitado, tal vez como resultado de algún sismo. Una vez reconstruido, el horno siguió siendo utilizado, tal como atestigua la considerable acumulación de carbón y ceniza en sus inmediaciones.

Asimismo, no cabe duda que la estructura de lado oeste de la plaza 1 es de tiempos coloniales. Tal como ya se anotó, la sección sur de dicha estructura fue la iglesia (Fig 16) y que obstruye el camino Inca que ingresa a la plaza del lado oeste. Dicha estructura, especialmente en la sección de la iglesia, al igual que el horno, había sido dotada de un muro de contención levantada en base a cantos rodados y que llegó a cubrir el muro de adobes con enlucido blanco establecido inicialmente.

Muchas de las reconstrucciones no necesariamente dejaron evidencias claras con respecto si dichas modificaciones tomaron lugar en tiempos Inca o con posterioridad. Un caso concreto es la plataforma del lado este de la plaza 1 que es considerablemente alto. La interrogante es si la plataforma fue construida desde un inicio teniendo dicho tamaño, o si su tamaño final es resultado de varias etapas de construcción. De la primera excavación de prueba efectuada al frente de una plataforma del lado sur, se pudo constatar que la plataforma creció de manera gradual durante el transcurso del tiempo. Efectivamente, con las excavaciones se puso al descubierto la presencia de 3 pisos sucesivos. Por cuanto dicha excavación no llegó hasta el nivel estéril, existe la posibilidad que pisos adicionales existan a mayor profundidad, indicando así que la plataforma alcanzó mayor altura con el paso de los años. 


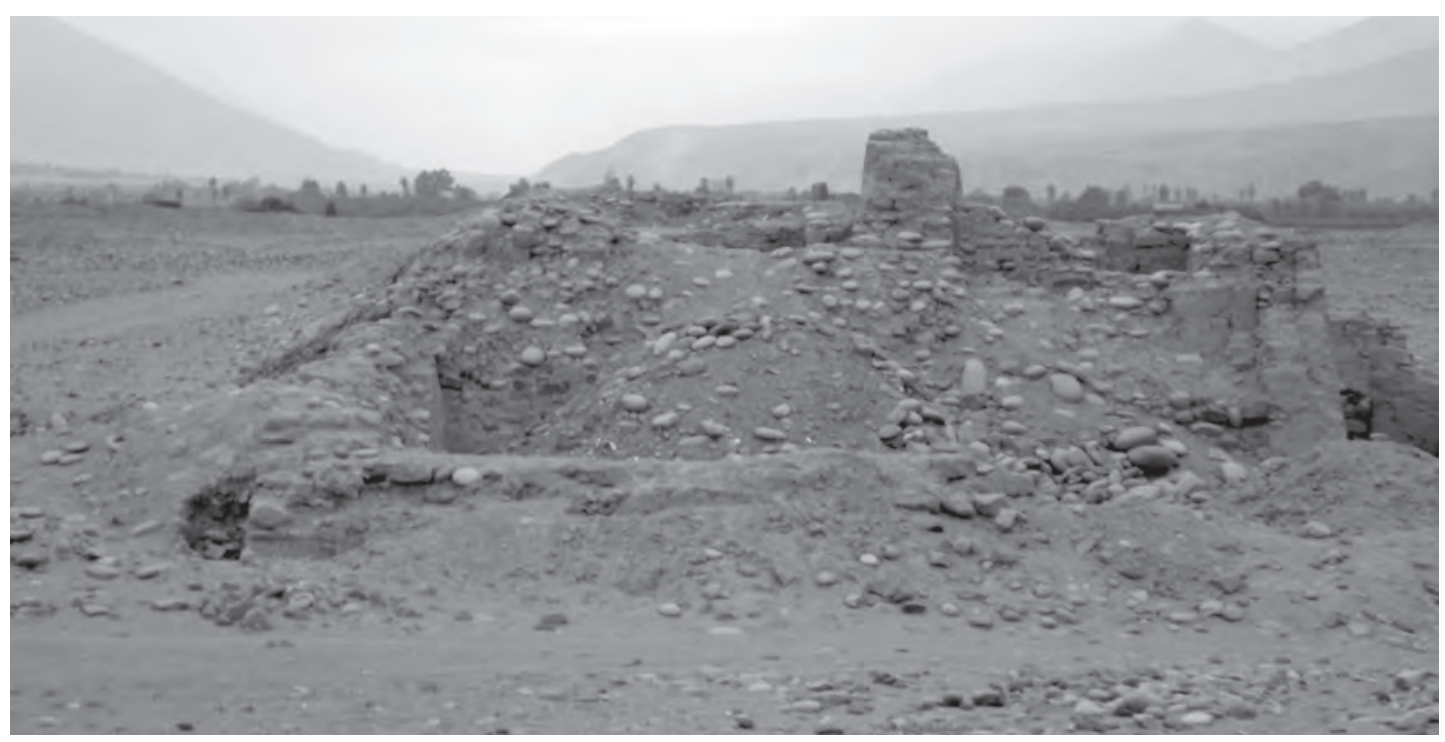

Figura 16: Iglesia ubicada al lado oeste de la Plaza 1.

\section{LAS EXCAVACIONES DE PRUEBA}

Con el objetivo de determinar el origen de las estructuras del área A, se llegó a excavar dos unidades de prueba, uno de 1 X $2 \mathrm{~m}$ y otro de 2 X $2 \mathrm{~m}$, las mismas que se efectuaron siguiendo niveles arbitrarios de $25 \mathrm{~cm}$. La primera unidad de excavación fue efectuada en la esquina nor-oeste de una estructura de forma cuadrada, ubicada cerca a la plataforma sur, al sur-oeste de la plaza 2 (Fig. 2). A una profundidad de $1,75 \mathrm{~cm}$ se llegó a determinar la presencia de un piso; un segundo piso fue descubierto a una profundidad de 2,4 $\mathrm{m}$ y un tercer piso a una profundidad de 2,8 m (Fig 17). En esta unidad no se llegó a mayor profundidad en tanto que el hoyo se hizo bastante angosto, existiendo la posibilidad que uno de los perfiles se derrumbara. La segunda unidad fue excavada al lado oeste del muro que divide a área A de área B, a corta distancia al oeste de una estructura rectangular. Aquí se excavó hasta una profundidad de $2 \mathrm{~m}$ cuando se llegó a suelo estéril.

De estas dos excavaciones de prueba quedó obvio que en la primera unidad se excavó rellenos que formaron parte de las estructuras y como tal fue difícil determinar una estratigrafía primaria. Sin embargo, la excavación fue útil para evaluar la secuencia de construcción y así conocer la asociación de los materiales con fases específicas.

Por lo tanto, los restos arqueológicos de Tambo Viejo utilizables como evidencia de la ocupación Inca constituyen tanto la arquitectura como la cerámica. Además, otros restos materiales, todos en excelente estado de conservación, fueron recuperados con las excavaciones. Esto incluye mate burilado, tejidos, cuerdas, instrumentos de hilar, redes, bolsas, utensilios líticos, figurinas, tupus, agujas, y otros utensilios personales. De todos estos, sin embargo, la cerámica es el material estilísticamente más sensible al cambio y sobre el cual contamos con mayor información comparativa. Por lo tanto, la cerámica sirve como indicador básico de tiempo y estilo. Dicho esto, una tarea de los trabajos en Tambo Viejo fue efectuar un estudio detallado de la cerámica, determinar sus sub-divisiones estilísticas, así como evaluar cuáles fueron contemporáneos y cuáles fueron de tiempos diferentes. Al hacer todo esto, se prestó atención en determinar la asociación definitiva de grupos específicos de cerámica con otros restos culturales, incluido la arquitectura.

Las dos excavaciones de prueba son mínimas y la principal razón por las que excavaciones más extensas no se efectuaron fue el tiempo limitado del que se disponía. Sin embargo, los datos recupe- 


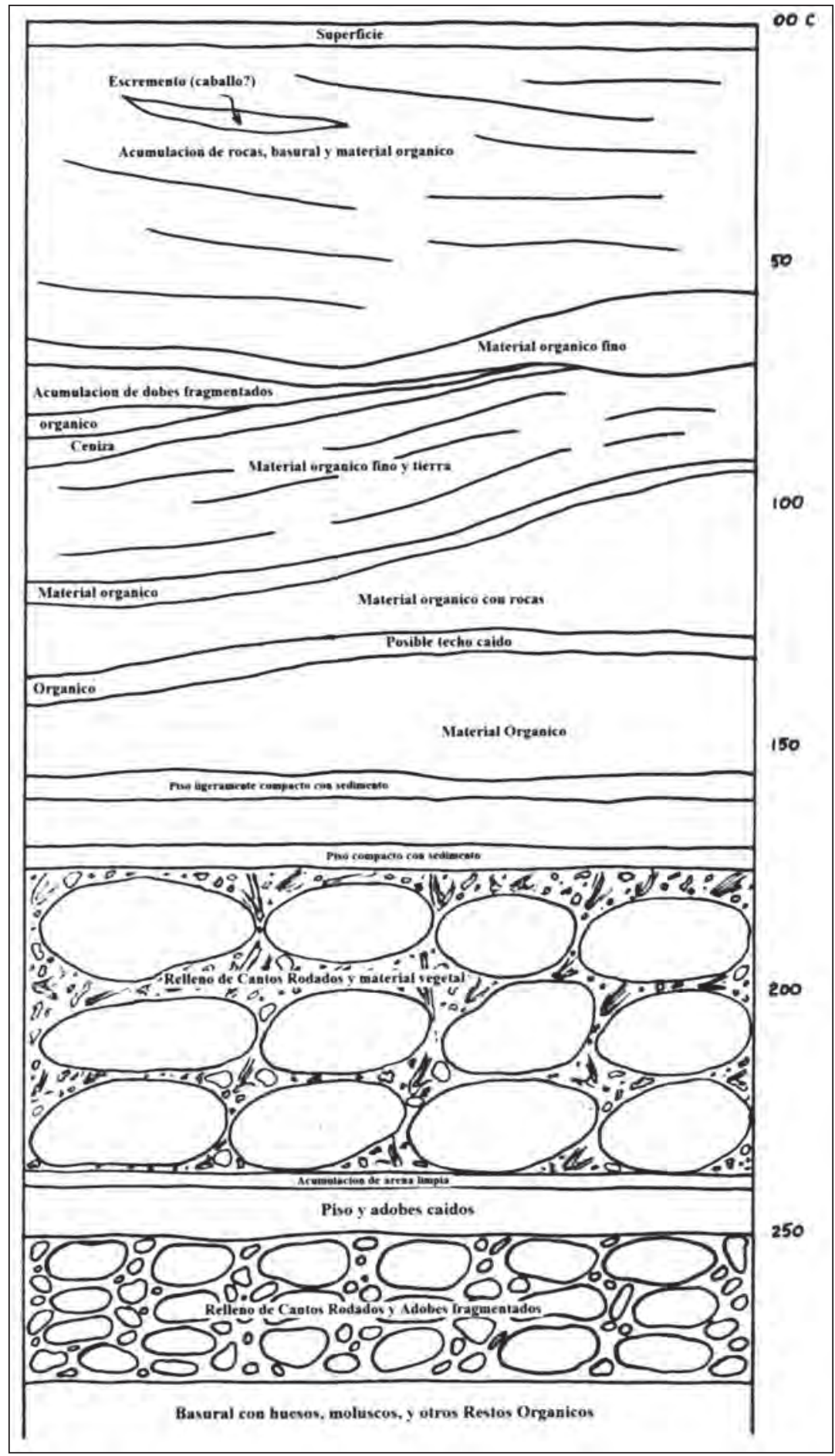

Figura 17: Dibujo de perfil Norte de la primera prueba de excavación. 
rados con las excavaciones permitieron determinar varios aspectos importantes con respecto a la ocupación del área sur-este de Tambo Viejo. Entre éstas, se conoce:

1. Los fragmentos de cerámica Inca ocurren en todos los niveles de la segunda unidad, así como en todos los niveles excavados de la primera unidad;

2. En asociación a los fragmentos de cerámica Inca, ocurre la misma variedad de cerámica local en todos los niveles excavados y en ambas unidades excavadas;

3. Los restos coloniales ocurren en ambas unidades hasta una profundidad de $75 \mathrm{~cm}$ (tercer nivel), aunque son raros;

4. La colección de cerámica de superficie del área A, así como de varios sectores fuera de ésta, son idénticos en composición a los fragmentos provenientes de las excavaciones;

5. En la superficie del área A, y en las unidades de excavación, es rara la presencia de otros estilos cerámicos pertenecientes a periodos anteriores.

Las conclusiones que se pueden extraer de las excavaciones de prueba realizadas en Tambo Viejo son:

1. La ocupación entera del área A del sitio pertenece al periodo Inca;

2. La ocurrencia esporádica de algunos fragmentos de cerámica perteneciente al periodo Intermedio Temprano indica que la ocupación Inca fue edificada en las inmediaciones de una zona previamente ocupada.

3. La ocupación colonial está representada por aproximadamente una cuarta parte del material de los rellenos en sus partes superiores.

En general, las deposiciones de área A parecen haber sido acumulados durante un periodo relativamente corto. En el caso de la primera unidad de excavación, se definió la presencia de por lo menos tres fases de construcción edificadas durante un tiempo relativamente corto tal como sugiere la homogeneidad de la mayoría de los materiales. En el caso de la segunda unidad de excavación, consistente al parecer de una deposición original, pero sugiere igualmente un tiempo bastante breve. Por ejemplo, los fragmentos de lo que parece ser una entera vasija fueron recuperados en diferentes niveles. Al mismo tiempo, el estudio de la cerámica indica que los fragmentos que ocurren en diferentes niveles no muestran ninguna diferencia estilística. La sección perteneciente al análisis de la cerámica proveniente de Tambo Viejo será presentada en una próxima oportunidad.

\section{Otros Sitios InCA del VALLE de Acarí}

Existen más de cien sitios arqueológicos dispersos a lo largo del curso del río Acarí (Valdez 2000a). De todos estos sitios, Sahuacarí y Otapara son los que resaltan con mayor facilidad, especialmente Sahuacarí (Fig 18). Este último se encuentra en las pendientes del cerro inmediato a Acarí Viejo, directamente al nor-este de Tambo Viejo y desde donde se puede divisar gran parte de la sección agrícolamente más productiva del valle. Aproximadamente a $20 \mathrm{~km}$ río arriba se encuentra Otapara, establecido sobre una colina con amplia visibilidad hacia el valle. En este sentido, ambos sitios fueron establecidos fuera de las áreas agrícolas, pero con acceso directo a ellas. Las estructuras de Otapara están bastante erosionadas y es poco lo que se puede decir de ésta, excepto su relación cronológica con Tambo Viejo.

Por su parte, Sahuacarí está en buen estado de conservación, excepto el derrumbamiento de las estructuras debido a su ubicación en una pendiente. Efectivamente, las estructuras de este sitio habían sido levantadas sobre terrazas artificiales y los muros hechos de piedras extraídas del mismo cerro, unidas con barro. Contrario a Tambo Viejo, los cantos rodados no fueron utilizados en Sahuacarí. Por esta razón, el sitio aparece perfectamente camuflado en tanto el color de los muros (pirca) es la misma que del cerro, lo que hace difícil obtener buenas fotografías del sitio. La mayoría de las estructuras son cuadradas, con una dimensión de 3 X 3 m como promedio. Entre las varias estructuras también es todavía observable la presencia de pasadizos que conecta las varias secciones del sitio. 


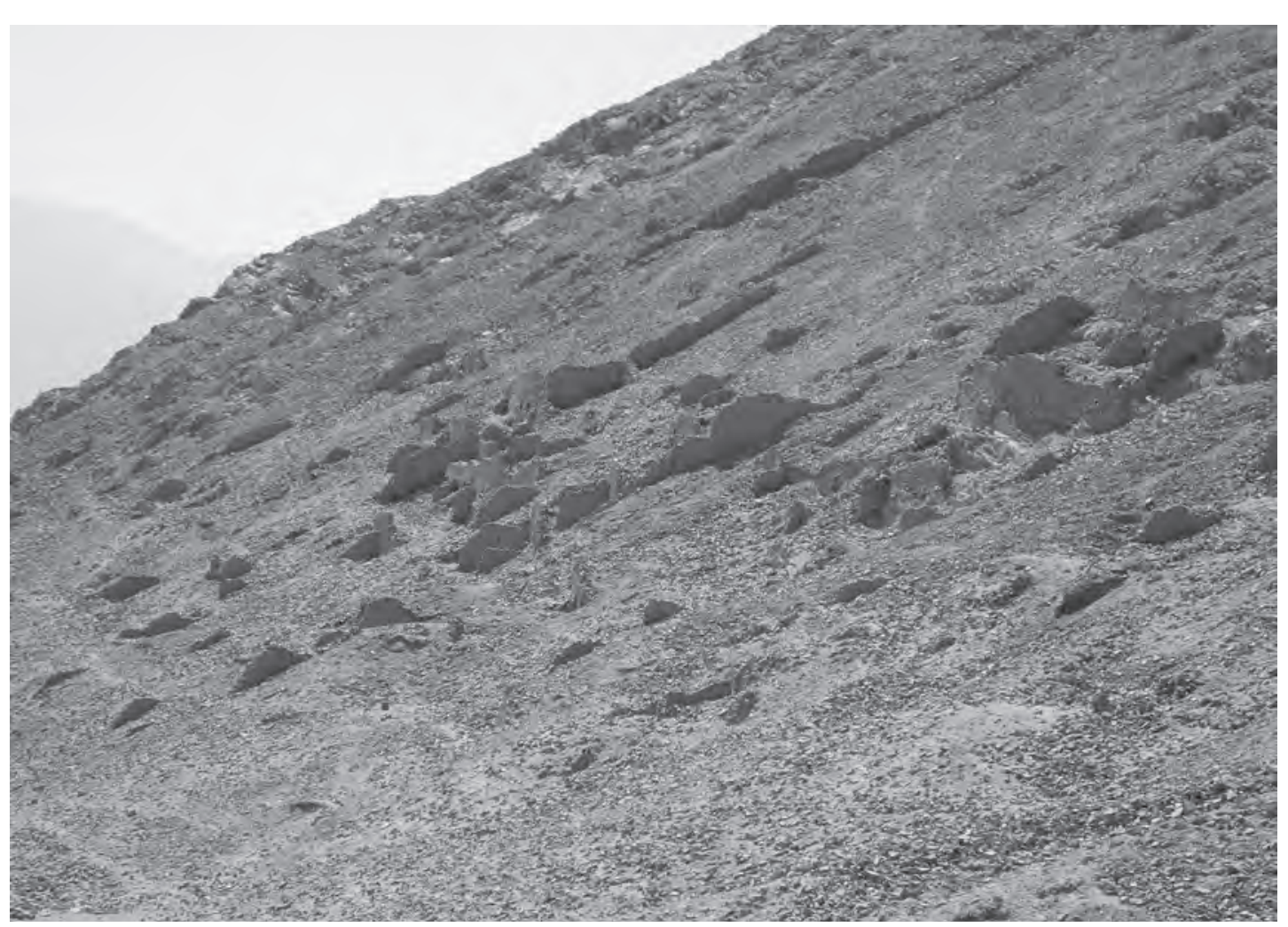

\section{Figura 18: Sitio arqueológico de Sahuacarí.}

Algunas de las estructuras de Sahuacarí se han preservado manteniendo más o menos su tamaño original (Fig 19), pero muchas otras se han derrumbado, quedando solamente la sección de la base de las estructuras. Los muros mejor preservados alcanzan una altura de hasta $3 \mathrm{~m}$ y como tales más altos que los muros encontrados en el mismo Tambo Viejo. A una altura entre 1,2 y 1,8 m aparecen pequeños nichos cuadrangulares $(15 \times 15 \mathrm{~cm}$ ), en el lado interno de las estructuras (Fig 20). Al mismo tiempo, se pudo constatar la presencia de pequeños accesos que miden $60 \mathrm{~cm}$. Igualmente, en asociación a las estructuras existen pequeñas estructuras rectangulares y hundidas que tal vez funcionaron a modo de depósitos.

El sitio de Sahuacarí en general ofrece problemas muy importantes. La cerámica encontrada en la superficie del sitio es del mismo tipo que de Tambo Viejo. Si existe alguna diferencia, ésta pueda que sea en la selección de algunas variedades especificas, pero esto no ha sido determinado. Sin embargo, la arquitectura del sitio es diferente de las presentes en Tambo Viejo. Tal vez esta diferencia sería menos notable si los muros de Tambo Viejo estarán mejor preservados. La diferencia más obvia es que los muros fueron construidos en su totalidad de piedras del mismo cerro y donde destaca la presencia de los nichos. De este modo, en Acarí encontramos dos sitios vecinos y contemporáneos construidos de maneras de todo diferentes.

La explicación por su puesto es que Sahuacarí tal vez representa una construcción local establecida antes de la llegada Inca al valle. Sin embargo, las estructuras de Sahuacarí tienen algunos elementos Inca, como es el caso de clavijas de piedra que sobresalen de los muros, además de los mismos nichos. Asimismo, la forma como las piedras de campo fueron utilizados es muy parecidos a la forma como los cantos rodados fueron empleados en Tambo Vejo. Mientras en Tambo Viejo es notable el plan previamente concebido, Sahuacarí no presenta orden alguno y de este modo tiene mucho en 


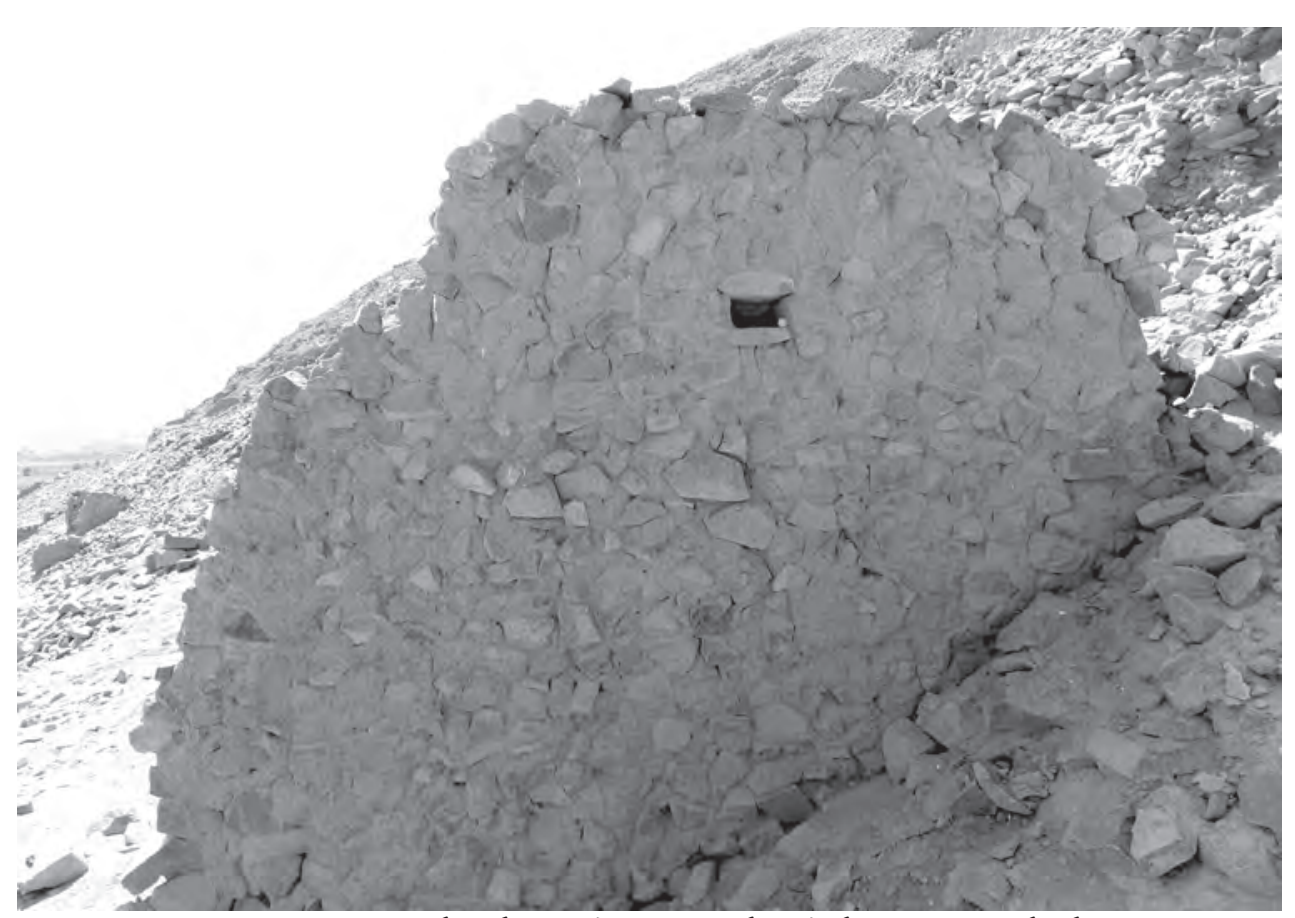

Figura 19: Estructura de Sahuacarí manteniendo más de tres metros de altura.

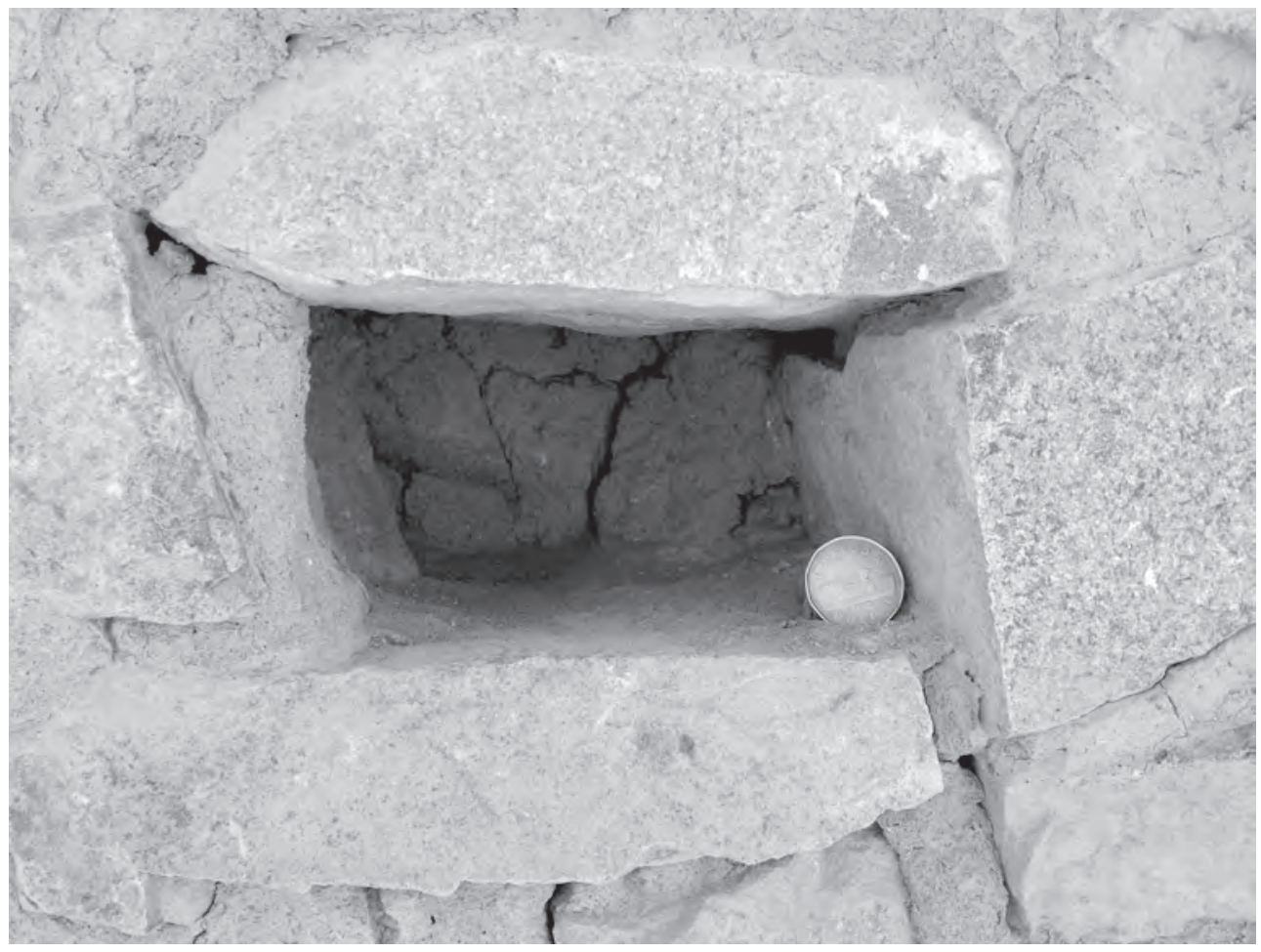

Figura 20: Pequeño nicho de una estructura de Sahuacarí. 
común con otros sitios contemporáneos de la región de Chala. De este modo, el lugar de Sahuacarí en relación a Tambo Viejo permanece poco esclarecido. La interrogante es por su puesto, cuál fue el patrón de construcción local antes de la llegada Inca, y fue teniendo en mente esta interrogante que se inspeccionó al sitio de Sahuacarí. Tanto la cerámica de la superficie del sitio, como la arquitectura todavía no permiten afirmar o negar el origen Inca o pre-Inca de Sahuacarí.

\section{ReLación de TAmbo Viejo con otros Sitios InCA}

Un estudio comparativo de los varios sitios Inca de la costa sur podría ser muy beneficioso para comprender mejor el patrón Inca y determinar la forma cómo dicho patrón fue empleado en esta región. Desafortunadamente, muchas estructuras Inca han sido destruidas antes que los especialistas tengamos la oportunidad de estudiar y aprender de cada uno de ellos. Este es el caso de Paredones en Nasca y La Centinela en Chincha (Morris y Santillana 2007; Morris y Von Hagen 2011: 146), para citar dos ejemplos. Sin embargo, otros sitios Inca todavía se mantienen parcialmente intactas y así permiten hacer algunas comparaciones. Lo ofrecido aquí no pretende ser una comparación exhaustiva, sino la intención es sólo ver si existen patrones comparables a Tambo Viejo.

Los sitios Inca de la costa sur mejor documentados son obviamente Tambo Colorado en el valle de Pisco (Hyslop 1984: 108-111; Protzen 2006; Protzen y Morris 2004; Morris y Von Hagen 2011: 142) y las estructuras Inca de la Hacienda San José, cerca a Ingenio. Datos comparativos también existen para los sitios de Paredones (Morris y Von Hagen 2011: 148-149) y del sitio Inca de la Hacienda Huayurí, al nor-oeste de Nasca. Por el sur, visitamos a la Hacienda Lampilla donde existe un importante sitio Inca. Más al sur hay importantes sitos Inca en la región de Atiquipa-Chala, de los cuales La Caleta obviamente fue un Tambo.

Por obvias razones, los sitios Inca de la costa sur no son idénticos, pero varios de estos sitios comparten elementos comunes. Al lado de todos estos sitios, Tambo Viejo parece ocupar una única posición geográfica, en tanto que es el sitio más sureño en relación a los demás, pero que comparte muchos rasgos con los sitios de Nasca, Ingenio y Pisco, por ejemplo. Por el sur, los sitios Inca son muy diferentes. El sitio de Lampilla tiene algunos rasgos en común con Tambo Viejo y la cerámica asociada al sitio es parecido al de Tambo Viejo. Sin embargo, el patrón general de Tambo Viejo y los otros sitios ubicados más al norte están simplemente ausentes en Lampilla.

En el sitio Inca de Ingenio uno encuentra de inmediato varios elementos en común con Tambo Viejo. El principal foco del sitio es una amplia plaza rectangular que dispone de dos plataformas bajas (Tambo Viejo tiene una), ubicadas al norte y sur de la plaza. La sección con la principal construcción del sitio está detrás de la sección más baja de las plataformas, al igual que en Tambo Viejo, y mantiene una orientación hacia el oeste. Las estructuras más formales del sitio también están detrás de la plataforma, al lado norte de la plaza. Entretanto, al lado sur de la plaza existen varios recintos rectangulares. Esta sección del sitio fue cortado por la Panamericana. Durante la inspección del sitio fue difícil determinar la presencia del camino Inca, pero es muy posible que ésta también haya sido borrada por la Panamericana. Los depósitos mencionados previamente están entre 0.5 y $1 \mathrm{~km}$ al oeste, sobre una elevación natural; así, al igual que en Tambo Viejo, los depósitos fueron establecidos a una distancia del centro principal.

La sección principal de Ingenio es más pequeña en relación al área A de Tambo Viejo. Las construcciones también son de pirca y adobe; estos últimos son iguales que los de Tambo Viejo. En lugar de los cantos rodados utilizados en Tambo Viejo, aquí se utilizaron piedras del campo, unidas con barro. Por lo general, la fundación de los muros es de pirca, mientras que la sección superior es de adobe. La más notable diferencia con Tambo Viejo es que en Ingenio existen los nichos trapezoidales, que es un sello Inca.

Las estructuras de Ingenio comparten varios rasgos comunes con Tambo Colorado y Paredones. El más común entre los 3 sitios es que las principales estructuras están inmediatas a las pendientes y donde las estructuras disponen de los nichos trapezoidales. En Paredones y Tambo Colorado los 
nichos son de doble jamba. Asimismo, en estos dos sitios las paredes están pintadas y con murales; los colores dominantes en Tambo Colorado son el rojo, amarillo y blanco. En Paredones se observaron la presencia del color rojo, aunque bastante deteriorados. Las estructuras de Tambo Colorado consisten de las principales estructuras y la amplia plaza principal en su parte frontal. Las construcciones mantienen una orientación hacia el sur (dirección de la plaza); pasando la plaza son observables los campos de cultivo y pasando estos aparecen terrazas antiguas, posiblemente establecidas en tiempos Inca. Para el caso de Paredones sólo quedan las principales estructuras, mientras el resto de lo que fue el sitio, como es el caso de la plaza principal, han sido del todo destruidos.

De los sitios de Tambo Viejo, Paredones, Ingenio y Tambo Colorado, este último es el mejor elaborado, mientras el más modesto es Tambo Viejo. En Tambo Viejo es mínimo el uso de los adobes y los nichos están del todo ausentes. Sin embargo, Tambo Viejo guarda mucho parecido con los otros sitios en su esquema general y plan, así como en el uso de piedras para los cimientos y adobes en las partes superiores de las estructuras.

Finalmente, están los sitios de San José y Huayurí. Las estructuras del primero constituyen el punto de enlace entre los sitios arriba mencionados y Tambo Viejo. El plano general de San José es bastante similar al de Tambo Viejo; a su vez, San José presenta muchos acercamientos con Paredones y Tambo Colorado. Por su parte, Huayurí es un pequeño sitio Inca dotado de una plaza rectangular y las respectivas construcciones adyacentes a la plaza. Todos estos patrones aquí mencionados brevemente están ausentes en los sitios Inca ubicados en los valles al sur de Acarí.

A su vez, la información disponible permite hacer algunas comparaciones generales entre Tambo Viejo y otros sitios Inca de la sierra. Desde que fueron publicados los primeros trabajos de Rowe (1944, 1946), los sitios Inca de la sierra han sido mejor descritos (Malpass 2009; McEwan 2006). Consideramos que dicha información es de mucha utilidad para evaluar qué rasgos comunes entre los sitios Inca de la sierra aparecen en Tambo Viejo. Aquí obviamente no pretendemos hacer una exhaustiva comparación, sino solamente anotar la presencia o ausencia de rasgos específicos, tanto en la arquitectura domestica como pública.

Para el caso de la arquitectura doméstica, Rowe (1946: 223) anotó que "las viviendas Inca fueron construidos en grupos, cada grupo encerrado por un muro que disponía de un solo acceso. Tales recintos son por lo general de forma rectangular donde la topografía lo permite, mientras que los asentamientos edificados en las pendientes fueron cuidadosamente acomodados al espacio disponible. Este tipo de residencia o recinto (Kancha) probablemente fue ocupado por una familia extensa." Además, Rowe anota que cada grupo residencial disponía de un patio (McEwan 2006: 175; Malpass 2009:53; Morris y Von Hagen 2011: 79-80).

Volviendo a Tambo Viejo, uno puede de inmediato notar que los recintos de las áreas C y D son comparables con la descripción de Rowe. Efectivamente, los recintos de Tambo Viejo disponen de sus propios patios y cada patio está asociado con varios cuartos donde probablemente residió una familia extensa. Al mismo tiempo, la evidencia superficial de Tambo Viejo deja la impresión que el patio fue el centro de las actividades, pues es ahí donde están presentes los batanes y sus respectivas parte activas. El patio también es el espacio donde se ha notado una mayor concentración de desechos domésticos. Finalmente, y al igual que las kancha Inca de la sierra, los recintos de Tambo Viejo, de lo que se pudo observar, también cuentan de una sola entrada.

En cuanto a la construcción de los recintos, Rowe (1946: 222) sostuvo que la mayoría de las viviendas en los alrededores de Cusco fueron construidas de piedras de campo o adobes unidas con barro, y que en planta tenían la forma rectangular. A una altura aproximada de 1,5 m las paredes se hacían más delgados, pero del todo enlucidos. En los detalles, las viviendas de Tambo Viejo no fueron construidas de la misma forma que las residencias Inca de Cusco, excepto que las piedras fueron establecidas de manera similar. Las estructuras de Tambo Viejo son más pequeñas y solamente los cimientos eran de pirca, siendo el resto de las estructuras levantadas -al parecer- de quincha. 
Con respecto a las estructuras públicas, Rowe (1946: 224, 227) anotó que los más conocidos monumentos de arquitectura Inca fueron construidos no por propietarios individuales, sino por el estado, siguiendo un plano elaborado y utilizando el trabajo de los mitayos. Los arquitectos y maestros de la construcción fueron especialistas. El estado llegó a construir una gran variedad de palacios, templos, depósitos, fortalezas, terrazas agrícolas y tumbas, algunos de los cuales siguiendo un diseño que derivó de las estructuras domésticas, mientras que otros fueron adaptados a usos particulares. Una de las estructuras públicas que derivó de estructuras residenciales, en la opinión de Rowe, fue el mismo Qori Kancha.

El sector del centro administrativo Inca de Tambo Viejo, obviamente no fue construido por propietarios individualmente, sino todo el conjunto de las estructuras parecen haber sido establecidas siguiendo un plano diseñado por especialistas. En otras palabras, quienes estuvieron detrás de la ejecución del establecimiento de tales estructuras siguieron un plan previamente concebido, la misma que seguía un modelo Inca.

En cuanto se refiere a estructuras públicas derivadas de diseños de estructuras habitacionales, este también se hace manifiesto en Tambo Viejo. Primero, la forma de los recintos es rectangular, excepto cuando la topografía no lo permitió; en este último caso, los constructores de Tambo Viejo adaptaron las estructuras a la topografía. Tal como se anotó en las secciones anteriores, el plan del centro administrativo de Tambo Viejo fue adaptado al contorno del escarpado, pero manteniendo en lo posible la forma rectangular. Segundo, uno también puede notar una semejanza de las estructuras de Tambo Viejo con la kancha Inca. En este caso, la plaza 1 es el equivalente del patio, el centro de las actividades. La plaza 1 es el lugar de entrada del camino Inca y el foco de las estructuras más sobresalientes del sitio, en particular de la plataforma del lado este. Las residencias y otras estructuras del sitio fueron edificadas en los alrededores de la plaza.

Es de particular interés anotar la presencia de la plataforma baja ubicada al lado sur de la plaza 1. Este tipo de construcción no es identificable en los recintos residenciales de Tambo Viejo. Sin embargo, en la región de Atiquipa y Chala, específicamente en La Caleta, Quebrada de la Vaca, Ocopa, y Cahuamarca, los patios de cada recinto disponen de una plataforma baja, idéntica a la de Tambo Viejo. Dichos mismos sitios también cuentan con una plataforma baja asociada a las residencias individuales, un rasgo también observado en Machu Picchu y que en la opinión de Rowe (1946: 224), constituirían las plataformas para dormir. Por lo tanto, la plataforma baja de Tambo Viejo es un modelo que tiene sus raíces en estructuras residenciales.

Una práctica común del estado Inca fue la reubicación de la población incorporada a la administración Inca a nuevos centros recientemente establecidos y que estaban más próximos a los terrenos de cultivo (Rowe 1946: 228-229). Los nuevos asentamientos fueron edificados por arquitectos especialistas y donde los diversos edificios públicos fueron construidos siguiendo el modelo Inca y con el trabajo de los mitayos. Los asentamientos también estaban en las proximidades de los mismos edificios públicos ocupados por las autoridades estatales. Para el caso especifico de Tambo Viejo, es importante anotar que la mayoría de la cerámica presente en el sitio es de origen local. Mientras que el desarrollo de dicha tradición local posiblemente continuó durante la ocupación Inca, se hace cada vez más evidente que a su llegada los Inca encontraron una población local. Así como se anotó, sitios asociados a dicha cerámica local están dispersos a lo largo del valle; de todos estos resaltan los sitios de Otapara, Lucasi y Sahuacarí, referidos en las líneas anteriores.

Es posible que una vez en el valle, el estado Inca re-ubicó a una porción de la población local hacia Tambo Viejo, no sólo para habitar las estructuras recientemente establecidas, sino también para participar en los trabajos efectuados en dicho centro. Nuevamente, la presencia de cerámica del mismo tipo tanto en Tambo Viejo como en otros sitios del valle sugiere que una buena proporción de los residentes de Tambo Viejo estaba compuesta de la población local. A su vez, esta misma evidencia sugiere que no toda la población fue reubicada hacia Tambo Viejo. Finalmente, no se descarta que población de valles vecinos también hayan sido reubicados hacia Tambo Viejo; pero, basado en la cerámica, dicha población debió ser mínima. 
De lo aquí anotado, Tambo Viejo guarda varias semejanzas con las construcciones Inca de la sierra, especialmente en cuanto al modelo se refiere. La forma como el sitio fue diseñado, en torno a una plaza, es un concepto Inca que se observa en muchos asentamientos Inca de importancia, caso Tambo Colorado.

\section{CONSIDERACIONES GENERALES}

Lo arriba señalado resume parte de los trabajos de investigación efectuados en Tambo Viejo y lo que se desprende de dichos estudios. Este trabajo se complementa con el análisis de la cerámica, cuyos resultados serán igualmente puestas a conocer en un próximo volumen de esta revista. Por cuanto no existe a la fecha un análisis detallado del significado de Tambo Viejo, esperamos que esta contribución sirva para prestar mayor importancia al sitio y a su vez dar inicio a nuevos trabajos de investigación. A falta de estudios más sistemáticos, se sigue desconociendo el significado de Tambo Viejo tanto a nivel local, como a nivel del Estado Inca en general. Resalta además la enorme extensión del sitio, la misma que denota la complejidad de sus estructuras, muchas aún bien preservadas no obstante el paso de los años y la intervención destructora de muchas actividades contemporáneas.

Lo expuesto en este trabajo demuestra a su vez lo rico que es el material Inca para conocer la forma como la administración Inca entró en contacto con otros pueblos (Menzel 1959), en algunos casos incluso logrando ajustarse a las condiciones locales. Lo aquí expuesto es una clara muestra de cómo un estado de las características de la administración Inca, cuando vio conveniente, minimizó sus esfuerzos al momento de incorporar nuevas poblaciones al interior del creciente imperio. En lugar de invertir mayores recursos, tanto humanos como materiales, el estado se conformó si las condiciones locales existentes eran favorables para la administración. Esta forma de acomodamiento posiblemente fue bien recibido por las poblaciones locales, como los de Acarí, para quienes la presencia Inca no necesariamente significó cambios de un carácter drástico y significativo. Siguiendo las recientes propuestas de Alconini y Malpass (2010: 281; Malpass y Alconini 2010: 3), el caso discutido aquí representa una forma de dominio indirecto del Estado Inca.

Mientras la población local fue al parecer partícipe del acomodamiento Inca, ya sea edificando las nuevas estructuras pero utilizando conocimientos locales, la administración Inca también fue hábil en insertar elementos que trajeron consigo y que simbolizaron la presencia del aparato estatal. Este es el caso de las plazas de forma rectangular conectadas a las principales vías de comunicación. Además están las estructuras identificables como kancha que nuevamente son rasgos propiamente Inca. Otro rasgo de particular importancia es que Tambo Viejo estaba bien articulado al resto del territorio Inca mediante el camino real Inca que precisamente cruza por la plaza principal del sitio. Finalmente, y al igual que otros sitios Inca de mayor importancia establecido a lo largo del imperio, Tambo Viejo disponía de los depósitos, aunque tal vez de la misma escala que de otros sitios Inca.

Así como ya se anotó, la incorporación de este valle al dominio Inca no necesariamente significó el término de la tradición local de Acarí. Por el contrario, ésta logró mantenerse tal vez en un esfuerzo de mantener su identidad. Este es un aspecto que se hace todavía más obvia en la cerámica manufacturada en este valle durante el tiempo de la ocupación Inca. El estilo local, si bien recibió influencia externa, fue hábil al seleccionar rasgos específicos que fueron incorporados al estilo local, pero una vez que fueron alterados. Este es el caso de los rasgos Inca que también fueron seleccionados y posteriormente representados en el estilo local. Como resultado, la cerámica propiamente Inca es mínima en Tambo Viejo. Lo mismo se puede advertir de la arquitectura Inca, lo que demuestra una vez más que la incorporación de otras tradiciones locales al imperio Inca no siempre resultó en la destrucción definitiva de las formas locales. Esta notable variación puede ser directo resultado y consecuencia de cómo una región o población fue incorporada al dominio Inca, donde pueblos como los del valle de Acarí parecen haberse sometidos de forma pacífica. La población local de este valle al momento de la llegada Inca posiblemente fue reducida y como tal incapaz de sostener una resistencia satisfactoria. 
Muchas veces la nomenclatura de Imperio, o Estado, deja la impresión que la administración Inca fue homogénea. Sin embargo, el estudio inicial de la ocupación Inca de la costa sur ya había permitido conocer que el Estado Inca no fue homogénea (Menzel 1959), en tanto que las tradiciones locales lograron mantenerse incluso hasta tiempos coloniales. Existen varias explicaciones para la continuidad de los estilos locales, la misma que incluye la forma como poblaciones determinadas fueron incorporadas, la forma como el Estado Inca llegó a supervisar a la población local, y por supuesto la corta duración del Estado Inca. Esta última en particular no permitió que la administración Inca dejara sus huellas de una forma más marcada y clara. Por lo tanto, y así como otros estudiosos del Estado Inca vienen reconocido (Morris 2007; Malpass y Alconini 2010: 3), el Imperio Inca fue compuesto por un mosaico de tradiciones locales, cuyas raíces retrocedían a varios cientos de años.

\section{BibliografíA}

ALCONINI, Sonia y Michael A. MALPASS

2010 "Toward a better understanding of Inka provincialism". En: Distant Provinces in the Inka Empire: toward a deeper understanding of Inka Imperialism, editado por M. A. Malpass \& S. Alconini, pp. 279-299. University of Iowa Press, Iowa City.

CIEZA DE LEÓN, Pedro

1973 [1553] La Crónica del Perú. Ediciones Peisa, Lima.

COBO, Bernabé

1956 [1653] "Historia del Nuevo Mundo”. En: Biblioteca de Autores Españoles XCII, pp. 5-275. Obras del padre Bernabé Cobo, Segunda Parte. Ediciones Atlas, Madrid.

D'ALTROY, Terence N.

2002 The Incas. Blackwell Publishing, Malden, MA.

D'ALTROY, Terence N. y Timothy K. EARLE

1992 "Inka storage facilities in the Upper Mantaro Valley, Peru". En: Inka Storage Systems, editado por T. Y. LeVine, pp. 176-205. University of Oklahoma Press, Oklahoma.

GASPARINI, Graziano y Luise MARGOLIES

1980 Inca architecture. Indiana University Press, Bloomington \& London.

HYSLOP, John

1984 The Inka Road System. Academic Press, New York.

1990 Inka Settlement Planning. University of Texas Press, Austin.

KENT, Jonathan D. y Makoto KOWTA

1994 "The cemetery at Tambo Viejo, Acari Valley, Peru". Andean Past 4: 109-140.

MCEWAN, Gordon F.

2006 The Incas: New Perspectives. W.W. Norton \& Company, New York \& London.

MALPASS, Michael A.

2009 Daily Life in the Inca Empire (second edition). Greenwood Press, Connecticut \& London.

MALPASS, Michael A. y Sonia ALCONINI

2010 "Provincial Inka studies in the Twenty-first century". En: Distant Provinces in the Inka Empire: toward a deeper understanding of Inka Imperialism, editado por M. A. Malpass \& S. Alconini, pp. 1 - 13. University of Iowa Press, Iowa City.

MENZEL, Dorothy

1959 "The Inca occupation of the South Coast of Peru". Southwestern Journal of Anthropology 15 (2): 125-142.

1976 Pottery Style and Society in Ancient Peru: Art as a Mirror of History in the Ica Valley, 1350-1570. University of California Press, Berkeley.

1977 The Archaeology of Ancient Peru and the work of Max Uhle. R. H. Lowie Museum of Anthropology, University of California, Berkeley.

MENZEL, Dorothy y Francis A. RIDDELL

1986 Archaeological Investigations at Tambo Viejo, Acari Valley, Peru, 1954. California Institute for Peruvian Studies, Sacramento. 
MORRIS, Craig

2007 "Andean ethnohistory and the agenda of Inka archaeology". En: Variations in the Expression of Inka Power, editado por R. L. Burger, C. Morris \& R. Matos Mendieta, pp. 1 - 10. Dumbarton Oaks, Washington, D.C.

MORRIS, Craig y Julián I. SANTILLANA

2007 "The Inka transformation of the Chincha capital". En: Variations in the Expression of Inka Power, editado por R. L. Burger, C. Morris \& R. Matos Mendieta, pp. 135-163. Dumbarton Oaks, Washington, D.C.

MORRIS, Craig y Adriana VON HAGEN

2011 The Incas: lords of the four quarters. Thames \& Hudson, London.

MURRA, John V.

1983 La organización económica del estado Inca. Siglo XXI, editores, México.

PROTZEN, Jean-Pierre

2006 "Max Uhle and Tambo Colorado a century later". Ňawpa Pacha 28:11-40.

PROTZEN, Jean-Pierre y Craig MORRIS

2004 "Los colores de Tambo Colorado: una reevaluación". Boletín de Arqueología PUCP 8: 267-276. Pontificia Universidad Católica del Perú, Lima.

RIDDELL, Francis A. \& Lidio M. VALDEZ

1987 "Hacha y la ocupación temprana del valle de Acarí". Gaceta Arqueológica Andina 16: 6-10.

ROBINSON, Rogger

1994 "Recent excavations at Hacha, Acari Valley, Peru". Andean Past 4:9-37.

ROWE, John H.

1944 "An introduction to the archaeology of Cuzco". Papers of the Peabody Museum of American Archaeology and Ethonology 27 (2).

1945 "Absolute Chronology in the Andean Area". American Antiquity 10 (3): 265-284.

1946 "Inca culture at the time of Spanish conquest". En: Handbook of South American Indians, Vol. 2, editado por J. H. Steward, pp. 183-330. Smithsonian Institution Bureau of American Ethnology Bulletin 143, Washington, DC.

1956 “Archaeological explorations in southern Peru, 1954-1955”. American Antiquity 22 (2): 135-151.

1963 "Urban settlements in ancient Peru". Ňawpa Pacha 1: 1-27.

SARMIENTO DE GAMBOA, Pedro

1999 History of the Incas. Dover Publications, New York.

VALDEZ, Lidio M.

1996 "Los depósitos Inka de Tambo Viejo, Acarí". Tawantinsuyu 2:37-43.

1998 The Nasca and the Valley of Acarí: Cultural Interaction in the Peruvian South Coast during the First Four Centuries A.D. Unpublished Ph.D. Dissertation, Department of Archaeology, University of Calgary, Calgary.

2000a “Arqueología del Valle de Acarí, Arequipa”. Boletín del Museo de Arqueología y Antropología 3 (12): 19-25. UNMSM, Lima.

2000b "La Tradición Cultural Huarato de Acarí y sus Relaciones con Nasca". Arqueología y Sociedad 13: 159 -171. UNMSM, Lima.

2009a "La investigación arqueológica en el valle de Acarí y la contribución de Francis A. Riddell". En: Arqueología del Área Centro Sur Andina: Actas del Simposio Internacional editado por M.S. Ziólkowski, J. Jennings, L.A. Belan \& A. Drusini, pp. 255-279. Andes 7, Boletín del Centro de Estudios Precolombinos de la Universidad de Varsovia.

$2009 \mathrm{~b}$ "Walled settlements, buffer zones, and human decapitation in the Acari Valley, Peru". Journal of Anthropological Research 65 (3):389-416.

2009c "Significado social de la cerámica Nasca temprano en el valle de Acarí, Perú". Revista Chilena de Antropología 20:15-36.

2012 "The earliest fortified settlements of the Acari Valley, Peru". Ponencia presentada al $40^{\text {th }}$ Annual Midwest Conference on Andean and Amazonian Archaeology and Ethnohistory. The Field Museum, Chicago, Febrero 25-26, 2012. 